\title{
Application of MODIS Products for Air Quality Studies Over Southeastern Italy
}

\author{
Adelaide Dinoi *, Maria Rita Perrone and Pasquale Burlizzi \\ CNISM, Physics Department, University of Salento, Via per Arnesano, 73100 Lecce, Italy; \\ E-Mails: maria.rita.perrone@le.infn.it (M.R.P.); pasquale.burlizzi@le.infn.it (P.B.) \\ * Author to whom correspondence should be addressed; E-Mail: adelaide.dinoi@ le.infn.it; \\ Tel.: +39-083-229-7498.
}

Received: 4 June 2010; in revised form: 24 June 2010 / Accepted: 5 July 2010 /

Published: 14 July 2010

\begin{abstract}
Aerosol optical thicknesses (AOTs) by the MODerate Resolution Imaging Spetroradiometer (MODIS) on-board Aqua and Terra satellites, and ground-based measurements of PM10 mass concentrations, collected over three years (2006-2008) at two suburban sites which are $20 \mathrm{~km}$ apart, are correlated to assess the use of satellite data for regional air quality studies over Southeastern Italy, in the central Mediterranean. Due to the geographical location, this area is affected by local and long-range transported marine, desert (from Sahara), and anthropogenic (from continental Europe) aerosols. 24-hour averaged PM10 mass concentrations span the $1.6-152 \mu \mathrm{g} / \mathrm{m}^{3}$ range. Yearly means of PM10 mass concentrations decrease from 2006 to 2008 and vary within the $26-36 \mu \mathrm{g} / \mathrm{m}^{3}$ range. Daily mean values of MODIS AOTs vary up to 0.8 at $550 \mathrm{~nm}$, while yearly means span the $0.15-0.17$ range. A first assessment of the regression relationship between daily averaged PM10 mass concentrations and MODIS-AOTs shows that linear correlation coefficients $(R)$ vary within the $0.20-0.35$ range and are affected by the sampling year and the site location. The PM10-AOT correlation becomes stronger $(0.34 \leq R \leq 0.57)$ when the analysis is restricted to clear-sky MODIS measurements. The cloud screening procedure adopted within the AERONET network is used in this study to select clear-sky MODIS measurements, since it allows obtaining larger $R$ values than the ones obtained using the cloud fraction MODIS product to select clear-sky MODIS measurements. Using three years of clear-sky measurements to estimate PM10 mass concentrations from MODIS-AOTs, the empirical relation we have found is: PM10 $\left(\mu \mathrm{g} / \mathrm{m}^{3}\right)=25\left(\mu \mathrm{g} / \mathrm{m}^{3}\right)+65\left(\mu \mathrm{g} / \mathrm{m}^{3}\right) \times$ AOT. Over $80 \%$ of the differences between the measured and satellite estimated PM10 mass concentrations over the three years are within \pm 1 standard deviation of the yearly means.
\end{abstract}


The differences between yearly means of calculated and measured mass concentrations that are close to zero in 2006, increase up to $4 \mu \mathrm{g} / \mathrm{m}^{3}$ at one site and $8 \mu \mathrm{g} / \mathrm{m}^{3}$ at the other site in 2008. The PM10 mass concentration decrease from 2006 to 2008 contributes to this last result. Our results demonstrate the potential of MODIS data for deriving indirect estimates of PM10 over Southeastern Italy. It is also shown that a stronger relationship between PM10 and MODIS-AOTs is obtained when the AOT is divided by the product of the mixing layer height with the ground wind speed and the analysis restricted to clear sky MODIS measurements. However, we have found that the stronger correlation $(0.52 \leq R \leq 0.66)$ does not allow a significant improvement of MODIS-based-estimates of PM10 mass concentrations.

Keywords: remote sensing; atmospheric aerosol; clouds

\section{Introduction}

Particulate Matter (PM) of natural and anthropogenic origin dominates the health effects of air pollution, as well as affecting the energy balance of the Earth-atmosphere system. Climate and human health effects depend on the size, amount, and composition of atmospheric particles, and as a consequence, in situ observations are usually used to determine PM mass concentrations and to characterize chemical and physical properties of sampled particles. PM sources vary over small spatial scales and the aerosol lifetime is of the order of less than an hour to several days, depending on particle size, chemical composition and atmospheric conditions. PM ground-based observations represent point measurements that are poor or even missing in many regions of the world and do not allow achieving the necessary coverage to map the regional to global distribution of PM. Satellite observations offer a much wider spatial view than in situ observations, and several studies have shown that they have great potential for deriving worldwide indirect estimates of ground PM [1-3]. However, satellite observations are less precise than in situ measurements. This suggests that they may be useful to improve the insight in regional PM distributions in combination with models and in situ measurements [2]. The satellite derived Aerosol Optical Thickness (AOT), which is the integral of the aerosol extinction from the ground up to the top of the atmosphere, is commonly used to provide a measure of the PM abundance. In particular, AOTs derived from the Moderate Resolution Imaging Spectral Radiometer (MODIS) have been compared with measured surface PM in several studies, due to the capability of the MODIS to provide near-daily global coverage and its good spatial resolution. Seven years of MODIS AOTs and ground PM2.5 measurements were used by [1] to present a comprehensive analysis of various aspects of PM air quality over one site in the Southeastern United States. Koelemeijer et al. [4] also explored the relation between MODIS AOTs and PM (both PM10 and PM2.5) for Europe. They found that linear correlation coefficients between AOTs and 24 hour-averaged PM10 and PM2.5 mass concentrations vary within the $0.15-0.35$ and $0.18-0.27$ range, respectively. Linear correlation coefficients varying within the $0.11-0.85$ range have also been found by [5]. They performed an inter-comparative and quantitative analysis of MODIS-AOTs and 
PM2.5 mass concentrations collocated in space and time, in 26 sites spread over India, Australia, Hong Kong, Switzerland, and the United States. The above mentioned studies have shown that the PM-AOT correlation depends on the region, aerosol type, aerosol vertical profile, and meteorological parameters. Therefore, empirical relations between AOT and PM10 or PM2.5 measurements which take into account meteorological parameters have also been reported in studies referring to several world sites. In particular, Koelemeijer et al. [4] found that the correlation between PM and AOT is improved when the AOT is divided by the mixing layer height and, to lesser extent, when it is corrected for growth of aerosol with relative humidity. On the contrary, Schaap et al. [6] found that the AOT to PM2.5 relationship was insensitive to the inclusion of the mixed layer height while it was quite affected by cloud-contaminated AOTs. In particular, they showed that the correlation coefficients for the AOTPM2.5 relations increased by restricting the analysis to clear-sky days. A better understanding of the main parameters affecting the strength of the AOT-PM correlation is therefore required to further contribute to the establishment of reliable satellite estimates of PM mass concentrations.

In this paper, we explore the relation between MODIS derived AOTs and 24 hour-averaged PM10 mass concentrations, since European air quality standards are at present set for 24-hour mean PM10 mass concentrations. The study is focused on a flat peninsular area in Southeastern Italy. This area is of particular importance as it is a crossroad where aerosols from different sources converge [7,8], such as fine anthropogenic aerosols from Europe, desert dust from North Africa and maritime aerosols from Mediterranean Sea. As a consequence, this area can be representative of many coastal areas of the central Mediterranean [9]. We use MODIS Terra and Aqua AOTs in addition to PM10 mass concentrations of two air quality stations, to investigate cloud cover, mixing layer height, and wind speed effects on the AOT-PM10 relationship, between 2006 and 2008. In addition, measurements from the AERONET sun/sky radiometer operating on the roof of the Physics Department of Universita' del Salento (Lecce University; $40.33^{\circ} \mathrm{N}, 18.10^{\circ} \mathrm{E}, 27 \mathrm{~m}$ a.s.1.), have been used to select clear sky MODIS measurements. The main statistical results on PM and AOT data are presented in Section 2. Then, the AOT-PM relationship is analyzed in Section 3. In addition to the MODIS cloud-cover product, the availability of sun-sky radiometer measurements performed within AERONET has been taken into account to select clear-sky MODIS-AOTs and to investigate how cloud-contaminated AOTs affect the AOT-PM relationship [10]. Sensitivity studies on the role of mixing layer height and ground wind speed are reported in Section 4. Summary and conclusions are in Section 5.

\section{Data Source and Statistical Analysis}

\subsection{Site Description and PM10 Data}

Arnesano $\left(40.334^{\circ} \mathrm{N}, 18.095^{\circ} \mathrm{E}\right)$ and Guagnano $\left(40.418^{\circ} \mathrm{N}, 17.964^{\circ} \mathrm{E}\right)$ are the selected monitoring sites of this study. They are air-quality stations of the Regional Environment Protection Agency (ARPA Puglia) network. The two suburban sites, which are $20 \mathrm{~km}$ apart, are located in a flat area of Southeastern Italy, $\sim 20 \mathrm{~km}$ away from the Adriatic and Ionian Sea, $100 \mathrm{~km}$ away from the Balkan coast, and $800 \mathrm{~km}$ away from the Northern Africa coast (Figure 1). Two important industrial areas are located in Southeastern Italy: a large steel factory that is about 75 and $60 \mathrm{~km}$ away from Arnesano and 
Guagnano, respectively, and a coal-fired power plant that is about 45 and $36 \mathrm{~km}$ away from Arnesano and Guagnano, respectively. A SWAM 5A monitor by FAI Instrument (Italy) was used to collect PM10 particles. Mass concentration measurements are based on the $\beta$-attenuation technique: the SWAM 5A monitor provides PM mass concentrations in accordance with the European Standard EN12341 and EN14907 and with a precision of $\pm 0.3 \mu \mathrm{g} / \mathrm{m}^{3}$ for daily mean values (www.faiinstruments.it). 24-hour-averaged PM10 mass concentrations from 2006, 2007, and 2008 are used in this study.

Figure 1. The geographical location of the study area (black dot) in the Mediterranean basin.

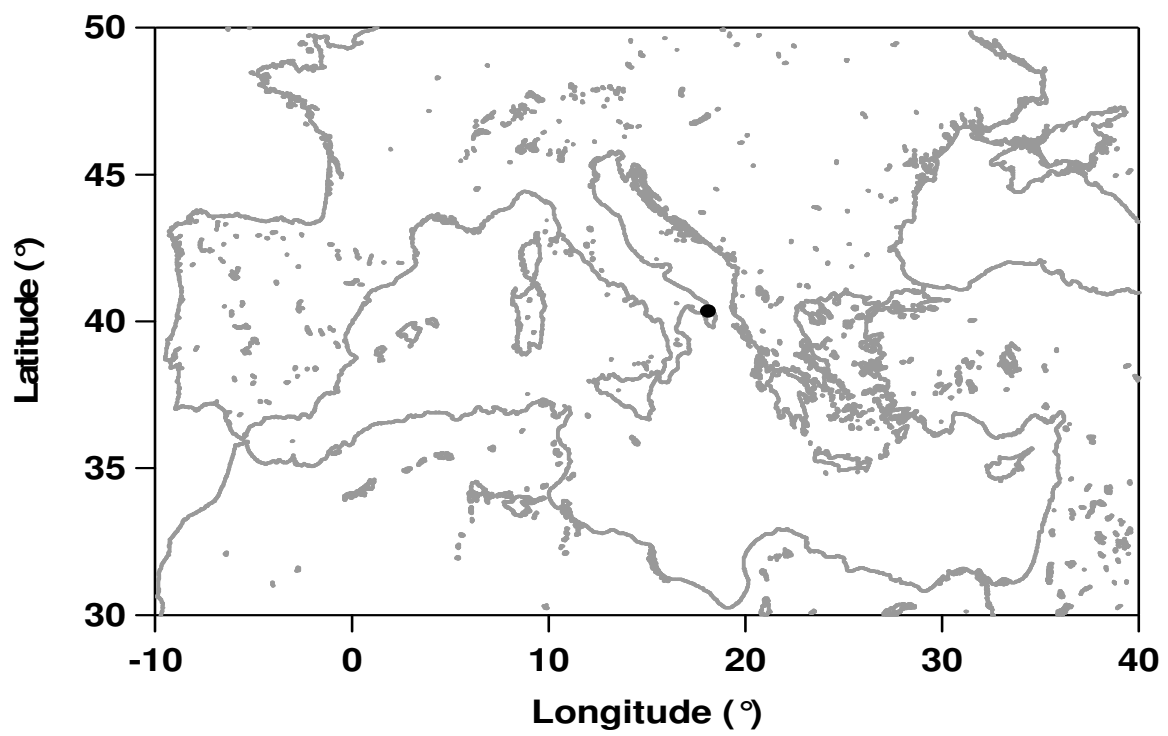

Figures $2 \mathrm{a}$ and $3 \mathrm{a}$ show the evolution with time of 24-hour-averaged PM10 mass concentrations at Arnesano and Guagnano, respectively. The grey lines in Figures $2 \mathrm{a}$ and 3a represent daily mean values and black lines represent monthly averaged values. 24-hour averaged PM10 mass concentrations span the $5.9-124 \mu \mathrm{g} / \mathrm{m}^{3}$ range at Arnesano and the $1.6-152 \mu \mathrm{g} / \mathrm{m}^{3}$ range at Guagnano. The high daily change in mass concentration revealed by Figures $2 \mathrm{a}$ and $3 \mathrm{a}$ is frequently observed in the Mediterranean area and surrounding regions [11]. Changes in air mass transport arriving from different sources toward the sampling point likely contribute to these results, as has been revealed in several studies on advection patterns over Southeastern Italy [8]. The mean values of the minimum (Min), maximum (Max), yearly, autumn-winter (AW, October-March), and spring-summer (SS, April-September) mean values of mass concentrations with \pm 1 standard deviation (SD) are reported in Table 1 for both sites. Figures $2 \mathrm{a}$ and $3 \mathrm{a}$ and Table 1 show that the yearly mean values of mass concentrations decrease from 2006 to 2008 in both sites: 55 and 45 days of the year have mass concentrations exceeding the 24-hour limit value of $50 \mu \mathrm{g} / \mathrm{m}^{3}$ at Arnesano and Guagnano, respectively in 2006. Conversely, 33 and 30 days/year have mass concentrations exceeding the 24-hour limit value at, respectively, Arnesano and Guagnano in 2008. AW-mass concentrations are a bit larger than SS mean values in both sites. The poor dependence on seasons of PM10 mass concentrations is typically found over Southeastern Italy and it is probably due to the poor evolution with seasons of the planetary boundary layer [12,13]. Both sites of this study are $20 \mathrm{~km}$ away from the Adriatic and Ionian Seas, and as a consequence, the evolution with time of the planetary boundary layer height is quite affected 
by sea breeze [14]. A marked dependence on seasons of PM mass concentrations is generally observed at inland sites where the planetary boundary layer is also characterized by a marked seasonal evolution [15]. Figures $2 \mathrm{a}$ and $3 \mathrm{a}$ allow the inference that mass concentrations of both suburban sites are quite well correlated. Linear correlation coefficients (R) and slopes (B) of regression lines fitting the scatterplots of Arnesano- versus Guagnano-PM10 mass concentrations are $\sim 0.8$ and 1, respectively.

Figure 2. Time evolution of (a) PM10 mass concentrations, (b) MODIS aerosol optical thicknesses (AOT), (c) mean mixing layer heights within 9-15 Universal Time (UT) time interval (Hmix), and (d) mean wind speed values within 9-15 Universal Time time interval (WSav), at Arnesano from 2006 to 2008. Grey lines show daily measurements, black lines show monthly means.
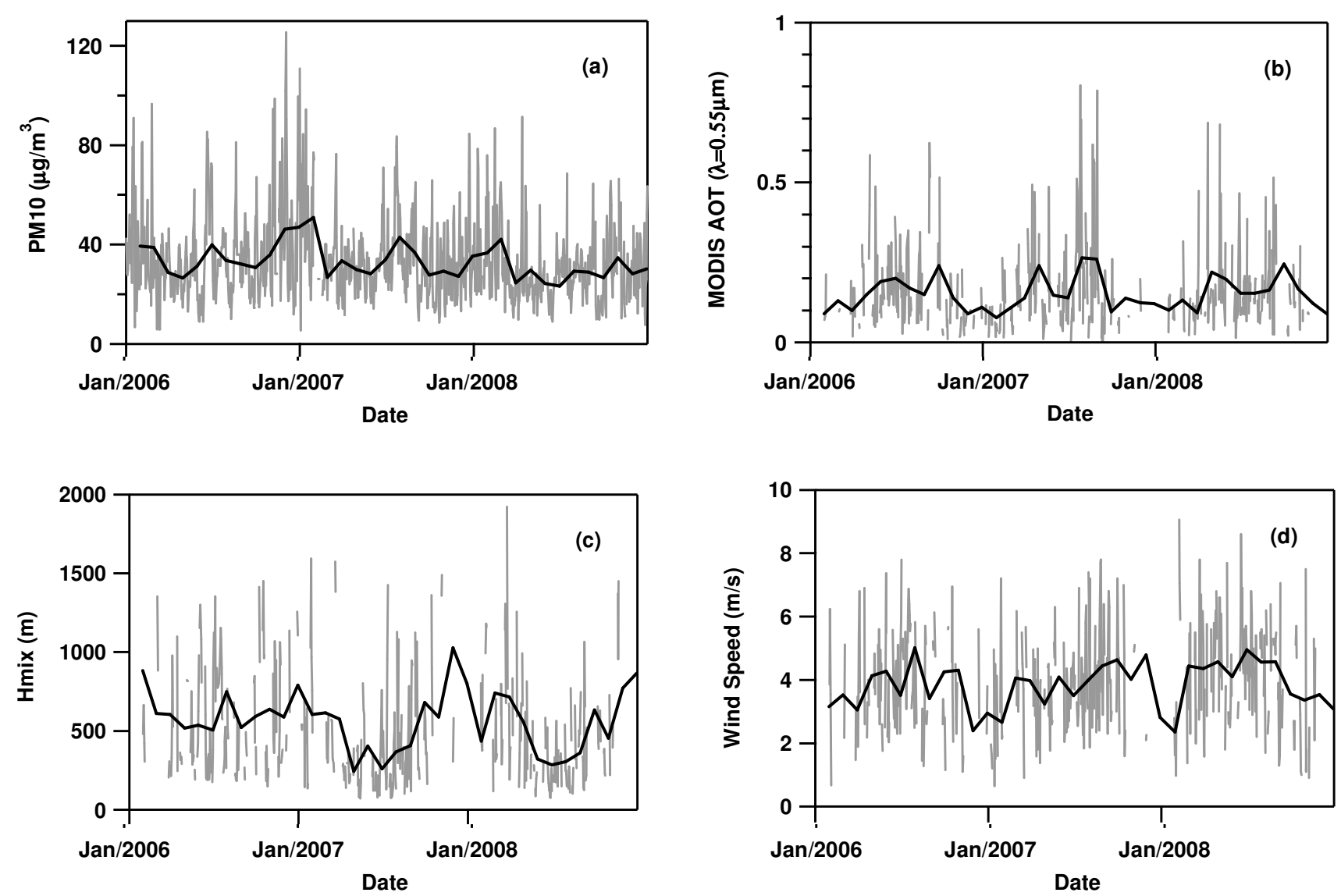
Figure 3. Time evolution of (a) PM10 mass concentrations, (b) MODIS aerosol optical thicknesses (AOT), and (c) mean mixing layer heights within 9-15 Universal Time (UT) time interval (Hmix), at Guagnano from 2006 to 2008. Grey lines show daily measurements, black lines show monthly means.
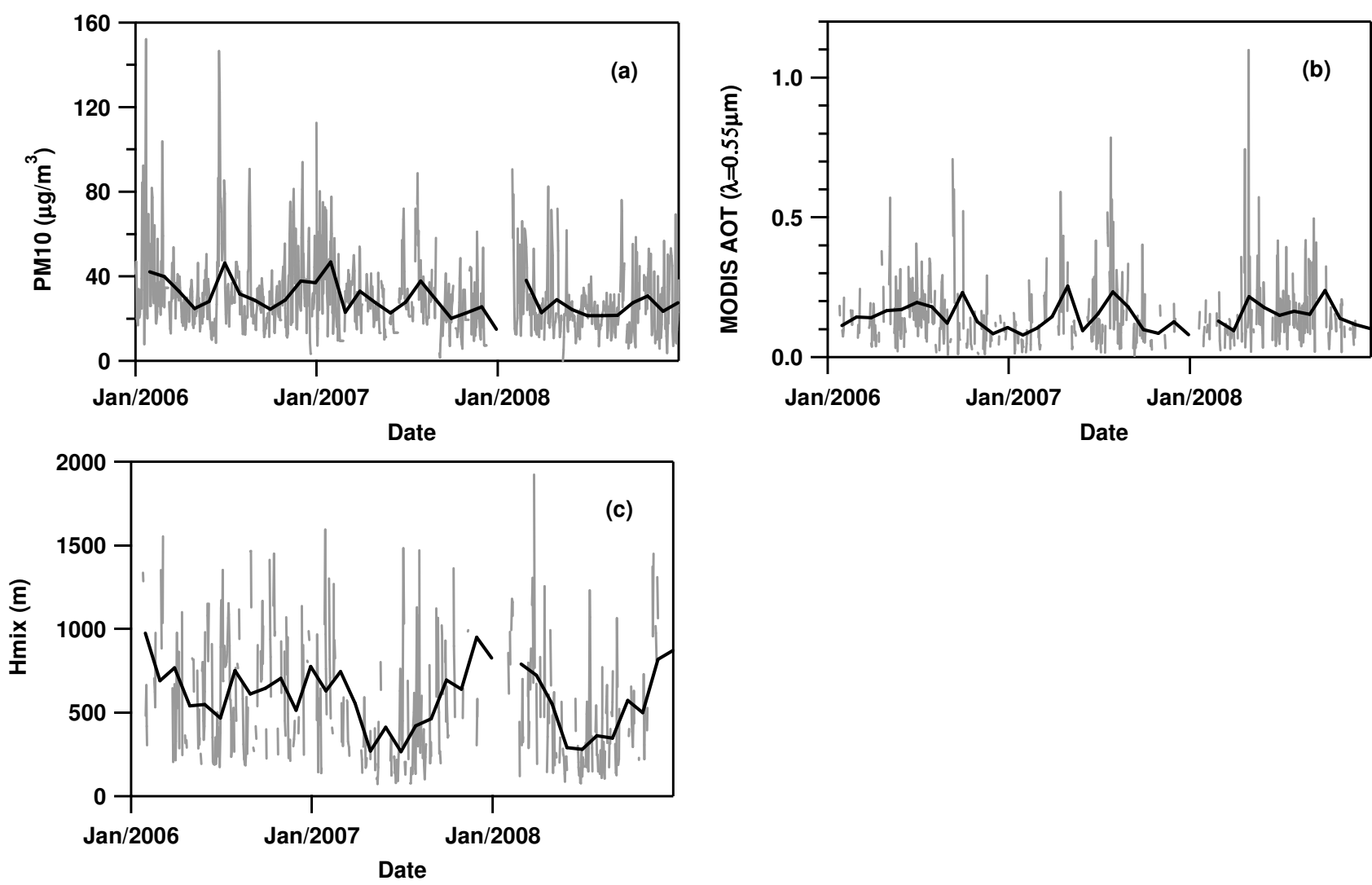

Table 1. Yearly means, minimum (Min), maximum (Max), autumn-winter (AW), and spring-summer (SS) mean values \pm 1 SD deviation of PM10 mass concentrations at Arnesano and Guagnano from 2006 to 2008.

\begin{tabular}{c|ccc|ccc}
\hline & \multicolumn{3}{c}{ ARNESANO } & \multicolumn{3}{c}{ GUAGNANO } \\
\hline & $\mathbf{2 0 0 6}$ & $\mathbf{2 0 0 7}$ & $\mathbf{2 0 0 8}$ & $\mathbf{2 0 0 6}$ & $\mathbf{2 0 0 7}$ & $\mathbf{2 0 0 8}$ \\
\hline Yearly mean $\left(\boldsymbol{\mu g} / \mathbf{m}^{\mathbf{3}}\right)$ & $36 \pm 18$ & $34 \pm 16$ & $30 \pm 14$ & $33 \pm 20$ & $29 \pm 16$ & $26 \pm 15$ \\
Min - Max $\left(\boldsymbol{\mu g} / \mathbf{m}^{\mathbf{3}}\right)$ & $5.9-125$ & $5.5-111$ & $7.7-91$ & $3.5-152$ & $1.6-113$ & $3.8-91$ \\
AW $\left(\boldsymbol{\mu g} / \mathbf{m}^{\mathbf{3}}\right)$ & $39 \pm 21$ & $35 \pm 18$ & $30 \pm 18$ & $36 \pm 20$ & $30 \pm 18$ & $29 \pm 17$ \\
SS $\left(\boldsymbol{\mu g} / \mathbf{m}^{\mathbf{3}}\right)$ & $32 \pm 15$ & $33 \pm 13$ & $28 \pm 14$ & $31 \pm 19$ & $28 \pm 14$ & $24 \pm 13$ \\
\hline
\end{tabular}

\subsection{Aerosol Optical Thicknesses by MODIS and Properties}

AOT data from the MODerate Resolution Imaging Spectroradiometer (MODIS) sensor are used in this study to explore the relation between satellite-derived AOTs and daily means of PM10 mass concentrations over Southeastern Italy. The MODIS sensor on board EOS-Terra and Aqua satellite has 36 spectral channels and a good temporal and spatial resolution [16]: Terra and Aqua satellites cross Europe near 10:30 and 13:30 local solar time, respectively, and as a consequence, at least two observations of any place in Europe are obtained per day. In addition, AOTs at $550 \mathrm{~nm}$ are reported 
at $10 \times 10 \mathrm{~km}^{2}$ resolution. Data from collection C005, which are based on the new operational algorithm V5.2, are used in this study [17,18]. In particular, the operational product Optical Depth Land and Ocean (AOT at $550 \mathrm{~nm}$ for both ocean (best) and land (corrected)) with best quality data (Quality Flag = 3) and recommended for quantitative studies [19], is used in this study, since the two PM monitoring sites are located on a narrow peninsula (Figure 1). The Optical Depth Land and Ocean product merges data from two different and independent algorithms, one for deriving aerosols over land and the other for aerosols over the ocean [20,21]. The main differences of aerosol retrieval algorithms for land and ocean are: (a) the land algorithm deduces surface reflectivity from the radiance measured at $2.13 \mu \mathrm{m}$ whereas the ocean algorithm assumes knowledge of surface reflectivity, (b) the land algorithm fits radiances at two wavelengths whereas the ocean algorithm fits radiances at six wavelengths to retrieve aerosol products, and (c) the land algorithm distinguishes between dust and non-dust, but otherwise uses prescribed combinations of coarse and fine mode aerosol for each region, whereas the ocean algorithm solves for both the type and relative amount of coarse and fine mode aerosol. The MODIS ocean-algorithm, besides AOTs, provides the AOT fraction contributed by the fine mode aerosol and the effective radius of the aerosol distribution. Therefore, the land and ocean retrieval products are largely independent of each other and, in general, the ocean products are considered much more accurate.

AOTs retrieved for cloud-free pixels, are available at the $550 \mathrm{~nm}$ band, which is traditionally used for climatological and air quality studies. MODIS AOTs have been validated against AOTs from the ground-based AERONET network. Validation shows that the retrieved AOT is within $\pm 0.05 \pm 0.15$ AOT over land and $\pm 0.03 \pm 0.05$ AOT over ocean [16-18]. Aerosol parameters from the Lecce University AERONET sunphotometer have also been compared to corresponding MODIS data to contribute to the validation of MODIS aerosol products over Southeastern Italy [22,23].

Daily AOT means are obtained in this paper by averaging all MODIS-Terra and MODIS-Aqua data points of a $20 \times 20 \mathrm{~km}^{2}$ box centered at the PM monitoring site. The correlation between MODIS-Terra and MODIS-Aqua measurements has also been investigated. Figure $4 \mathrm{a}-\mathrm{c}$ show as an example the scatterplots of daily-AOTs retrieved from MODIS-Terra measurements versus daily-AOTs from MODIS-Aqua measurements for 2006, 2007, and 2008. The data points of Figure 4 refer to a $20 \times 20 \mathrm{~km}^{2}$ box centered at Arnesano. In each plot of Figure 4, the solid line represents the linear regression line fitting the data points. Linear correlation coefficients $(R)$ and regression line parameters are also given. Correlation coefficients between Terra- and Aqua-AOTs vary within the 0.63-0.81 range. The Aqua and Terra discrepancies may arise from several factors such as sampling time, calibration differences, and uncertainties of the retrieval algorithm [3]. 
Figure 4. Scatterplot of daily-AOTs retrieved from MODIS-Terra measurements versus daily-AOTs from MODIS-Aqua measurements for a $20 \times 20 \mathrm{~km}^{2}$ box centered at Arnesano in (a) 2006, (b) 2007, and (c) 2008. The slope and intercept of regression line and linear correlation coefficient $(R)$ are also given in each plot.
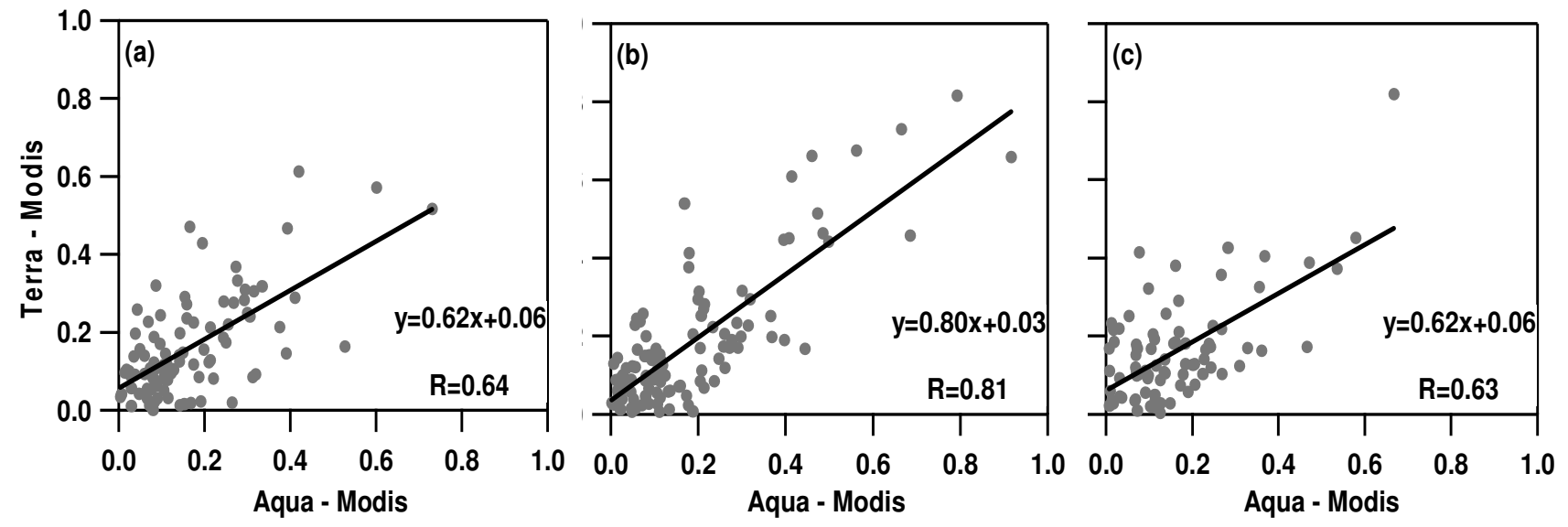

Figures $2 b$ and $3 b$ show the evolution with time of daily-mean-AOTs at Arnesano and Guagnano, respectively. In Figures $2 b$ and $3 b$, the grey lines represent daily mean values, while black lines represent monthly averaged values. The minimum (Min), maximum (Max), yearly, autumn-winter (AW), and spring-summer (SS) mean values of AOTs \pm 1 SD are reported in Table 2 for both sites. It is noteworthy that AW-AOTs are always smaller than SS-AOTs at both sites, despite the seasonal behavior of PM10 mass concentrations (Table 1). Ground-based lidar and AERONET sun-sky radiometer measurements have also revealed that SS-AOTs are on average larger in Southeastern Italy [13,24], in accordance with MODIS retrievals. In particular, lidar measurements have revealed that the height $\mathrm{z}^{*}$ at which the AOT reaches $90 \%$ of its maximum value is on average larger in SS. The larger $z^{*}$ and AOT values found in SS in Southeastern Italy can mainly be ascribed to the lack of rainy days which, during SS months, generally occurs on the Mediterranean basin and favors the accumulation of atmospheric particles. In addition, the larger solar flux typical of SS regimes favors the formation of photochemical smog during daytime. The frequent precipitations occurring in winter may also lead to low PM levels, in addition to low AOTs. Koelemeijer et al. [4] also found a seasonal trend of PM10 and MODIS-AOTs over Europe in 2003 similar to that of Southeastern Italy.

Table 2 shows that the Arnesano AOT mean values are rather similar to those of Guagnano during the three selected years. The spatial homogeneity of the AOT revealed by Figures $2 b$ and $3 b$ and Table 2 has been quantified in Arnesano- versus Guagnano-AOT scatter plots, which have provided linear correlation coefficients $(R)$ and regression line slopes $(B)$ of $\sim 0.90$ and $\sim 1$, respectively, in 2006 , 2007, and 2008. In addition, we have also found that the daily-mean-AOTs obtained by averaging all data points of a $20 \times 20 \mathrm{~km}^{2}$ box were well correlated $(R>0.95 ; B \cong 1)$ with the corresponding values obtained by averaging all data points of a $10 \times 10 \mathrm{~km}^{2}$ box centered at the same monitoring site. 
Table 2. Yearly means, minimum (Min), maximum (Max), autumn-winter (AW), and spring-summer (SS) mean values \pm 1 SD deviation of MODIS AOTs at Arnesano and Guagnano from 2006 to 2008.

\begin{tabular}{ccccccc}
\hline & \multicolumn{3}{c}{ ARNESANO } & \multicolumn{3}{c}{ GUAGNANO } \\
& $\mathbf{2 0 0 6}$ & $\mathbf{2 0 0 7}$ & $\mathbf{2 0 0 8}$ & $\mathbf{2 0 0 6}$ & $\mathbf{2 0 0 7}$ & $\mathbf{2 0 0 8}$ \\
\hline Yearly means & $0.16 \pm 0.11$ & $0.17 \pm 0.15$ & $0.16 \pm 0.12$ & $0.15 \pm 0.12$ & $0.15 \pm 0.13$ & $0.16 \pm 0.11$ \\
Min - Max & $0.002-0.62$ & $0.001-0.8$ & $0.015-0.74$ & $0.008-0.71$ & $0.005-0.78$ & $0.02-0.74$ \\
AW & $0.11 \pm 0.08$ & $0.11 \pm 0.07$ & $0.12 \pm 0.08$ & $0.12 \pm 0.08$ & $0.11 \pm 0.07$ & $0.12 \pm 0.06$ \\
SS & $0.18 \pm 0.12$ & $0.20 \pm 0.17$ & $0.18 \pm 0.14$ & $0.18 \pm 0.13$ & $0.18 \pm 0.14$ & $0.18 \pm 0.13$ \\
\hline
\end{tabular}

\section{Results on PM10-MODIS AOT Correlations}

Daily AOT means retrieved from MODIS-Terra and MODIS-Aqua measurements are plotted in this study against 24-hour averaged PM10 mass concentrations. As a first assessment of the regression relationship between AOT and PM10 mass, Figures 5a-c and 6a-c (grey dots) show the scatterplot of PM10 mass concentrations versus co-located in space MODIS-AOTs for Arnesano and Guagnano, respectively, for 2006, 2007, and 2008. In each plot, the grey solid lines represent the linear regression line fitting the data points. Regression line slope $(B)$, intercept $(C)$, and linear correlation coefficient $(R)$ are also given in each plot, in addition to the total number of data points $(N)$. Figures 5 and 6 show that $B, C$, and $R$ values depend on the sampling year and on the monitoring site, even if the two sites considered in this study are suburban sites located $20 \mathrm{~km}$ apart. The AOT-PM10 regression relationship is characterized by slightly larger $B$ and $R$ values at Guagnano. $R$ values span the $0.20-0.32$ and $0.25-0.35$ range at Arnesano and Guagnano, respectively. $B$ values vary within the $22-34 \mu \mathrm{g} / \mathrm{m}^{3}$ and $37-47 \mu \mathrm{g} / \mathrm{m}^{3}$ range at Arnesano and Guagnano, respectively. Intercept values represent background PM10 mass concentrations leading to null AOT values: i.e., the intercept represents the minimum mass concentration for which satellite derived AOT is sensitive. $C$ values vary within the $26-33 \mu \mathrm{g} / \mathrm{m}^{3}$ and $20-28 \mu \mathrm{g} / \mathrm{m}^{3}$ range at Arnesano and Guagnano, respectively.

Linear correlation coefficients of this study are in accordance with those by [4]. They explored the relation between satellite derived AOT and PM for Europe, making use of PM mass concentrations obtained from the European AIRBASE database. In particular, they found mean $R$ values equal to 0.21 and 0.35 by investigating the correlation between AOTs and daily-PM10 mass concentrations at 54 background and eight rural-background stations, respectively. Engel-Cox et al. [25] investigated the relationship of MODIS-AOTs with ground-based particulate matter data from the United States Environmental Protection Agency (EPA) monitoring networks from April to September, 2002. They found that linear correlation coefficients of AOTs and daily-PM10 mass concentrations varied within the 0.016-0.91 range and that they were larger in the Eastern and Midwest portion of the United States.

The PM-AOT correlation depends on the study area, aerosol load and type, aerosol vertical profiles, and meteorological parameters, as several authors have outlined. However, Schaap et al. [2] recently showed that cloud contamination in the MODIS AOT data may significantly affect the AOT-PM correlation. At a first glance, the scatterplots of Figures 5 and 6 (grey dots) show that several rather 
high AOT values are retrieved in days characterized by PM10 mass concentrations smaller than 20 $\mu \mathrm{g} / \mathrm{m}^{3}$ : this could occur due to the presence of cloud-contaminated AOT values.

The MODIS algorithm initially uses radiance measurements at a resolution of $0.5 \times 0.5 \mathrm{~km}^{2}$, even if AOTs are provided at a $10 \times 10 \mathrm{~km}^{2}$ pixel resolution. All 400 pixels $(20 \times 20$ pixels $)$, each having resolution of $0.5 \times 0.5 \mathrm{~km}^{2}$ within the $10 \times 10 \mathrm{~km}^{2}$ area, are first examined for cloud contamination using a spatial distribution technique [26]. The MODIS internal cloud mask at a $1 \times 1 \mathrm{~km}^{2}$ spatial resolution is also used to identify cirrus [27]. All pixels identified as cloudy or close to clouds are removed and a further analysis uses only cloud free pixels to retrieve AOTs. However, MODIS AOTs can still be cloud contaminated, despite the rigorous cloud screening procedure used. There are two main possible sources of cloud contamination: (a) residual cirrus contamination, since cirrus screening eliminates cirrus cloud contamination above a threshold of 0.01 [28,29], (b) high concentration of broken cloudiness, which may generate illumination of the aerosol field beyond the $500 \mathrm{~m}$ distance from clouds [30]. Therefore, the potential for contamination may increase as cloud fraction increases within the scene. The cloud fraction is defined as the fraction of the points which were rejected from the analysis by the aerosol algorithm.

The Cloud Fraction (CF) Land product from the MODIS land only algorithm (MOD04 L2) has been used in this study to estimate, for each retrieved AOT, the fraction of rejected pixels for the presence of clouds within the $20 \times 20 \mathrm{~km}^{2}$ analyzed box. AOTs have been grouped in different CF bins and Figure 7 a shows as an example, the normalized frequency distribution histogram versus CF bins for the AOT data set referring to Arnesano in 2006, 2007, and 2008. From Figure 7a, we observe that 64,70 , and $82 \%$ of AOTs have been retrieved by $20 \times 20 \mathrm{~km}^{2}$ boxes with a CF smaller than $10 \%$ in 2006, 2007, and 2008, respectively. On the contrary, less than 15\% of AOTs have been retrieved from boxes with a CF larger than 50\%. Then, PM-AOT data points have been grouped in different $\mathrm{CF}$ ranges to investigate how the regression relationship between AOT and PM10 mass is affected by the $\mathrm{CF}$. Figure $7 \mathrm{~b}$ shows, as an example, the histogram of linear correlation coefficients retrieved by taking into account Arnesano PM-AOT data points retrieved from boxes with $\mathrm{CF}<10,30,50$, and 70\%, respectively. Different bars are used to characterize $R$ values referring to 2006, 2007, and 2008. From Figure $7 b$, it is noteworthy that the PM-AOT relationship becomes stronger when the CF decreases: correlation coefficients on average become larger as CFs decrease. These last results indicate that the PM-AOT relationship is probably affected by cloud contaminated AOTs. Results similar to those of Figure $7 \mathrm{~b}$ were also found at Guagnano. Gupta et al. [5] also found stronger PM-AOT correlations by selecting MODIS-AOTs retrieved at lower CF conditions. Conversely, Gupta et al. [5] found that the linear correlation coefficient decreased with CF by analyzing seven years of MODIS-AOTs and PM2.5 mass concentrations retrieved at one site in the Southeastern United States. 
Figure 5. Scatterplot of PM10 mass concentrations versus co-located in space MODIS-AOTs at Arnesano for (a) 2006, (b) 2007, and (c) 2008. Slope, intercept and linear correlation coefficient $(R)$ are also given in each plot, in addition to the total number of data points $(N)$. Black dots represent data points referring to clear-sky MODIS measurements.
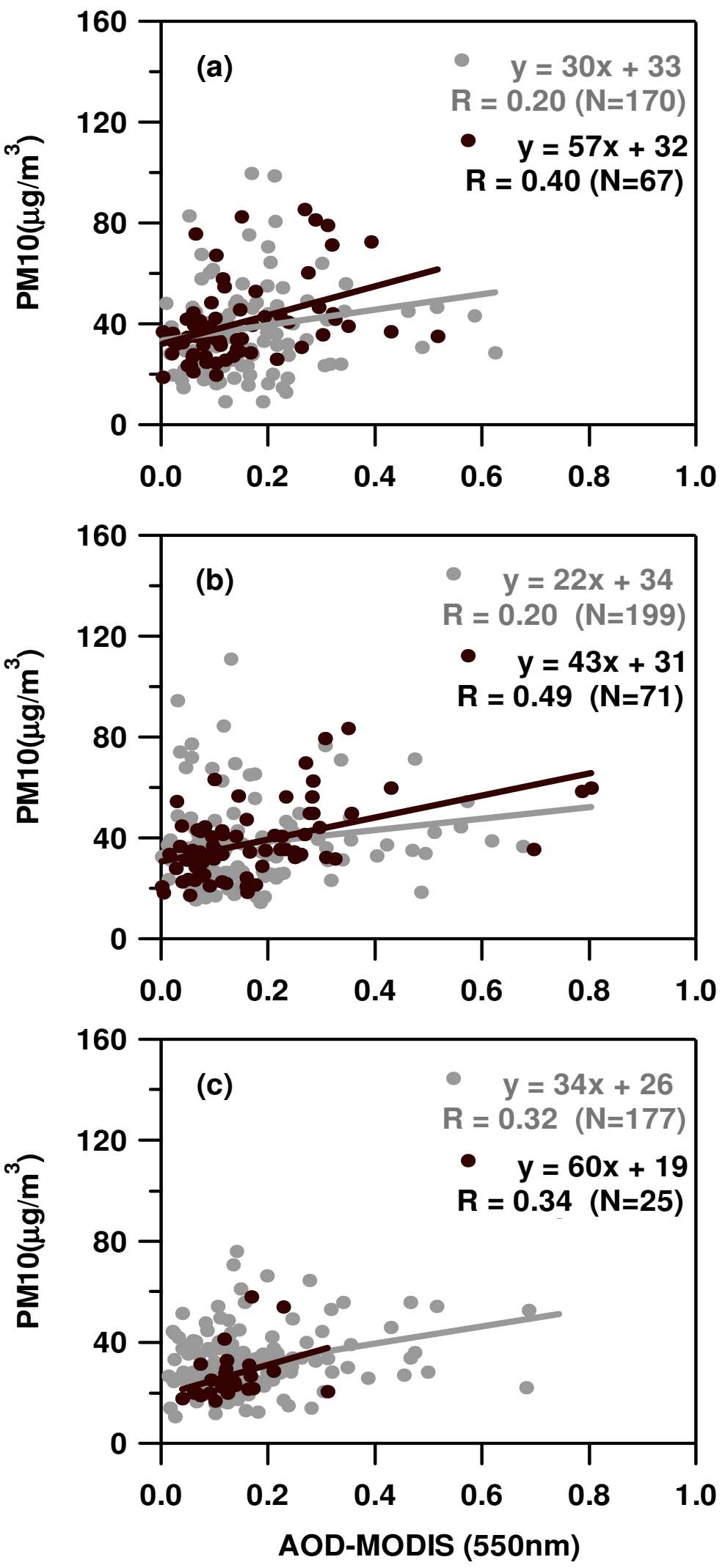
Figure 6. Scatterplot of PM10 mass concentrations versus co-located in space MODIS-AOTs at Guagnano for (a) 2006, (b) 2007, and (c) 2008. Slope, intercept and linear correlation coefficient $(R)$ are also given in each plot, in addition to the total number of data points $(N)$. Black dots represent data points referring to clear-sky MODIS measurements.
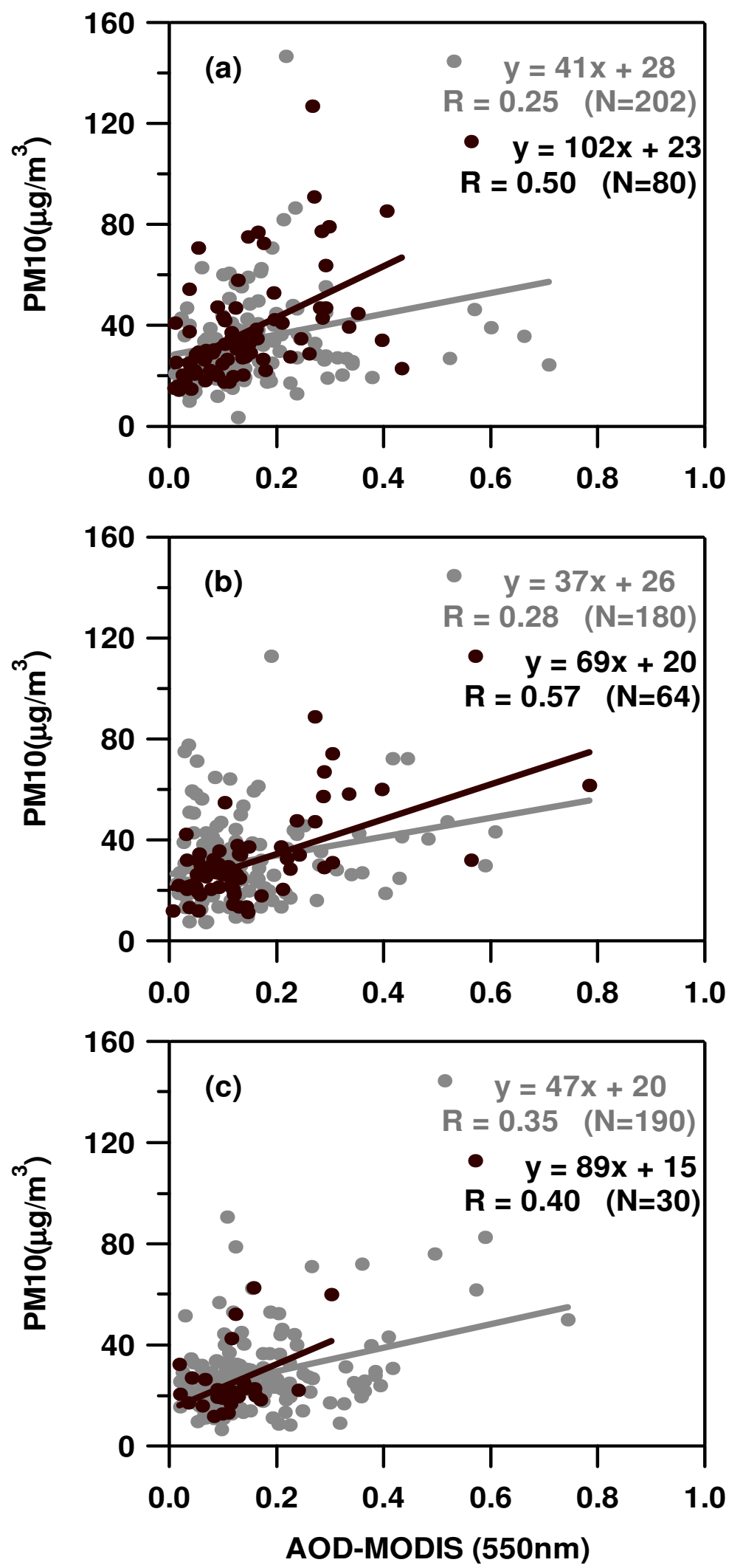
Figure 7. (a) Normalized frequency distribution histogram versus $\mathrm{CF}$ bins for the PM-AOT data set of Arnesano in 2006, 2007, and 2008. (b) Histogram of linear correlation coefficients retrieved by taking into account PM-AOT data sets characterized by $\mathrm{CF}<10 \%$, $30 \%, 50 \%$, and 70\%, respectively, in 2006, 2007, and 2008. (c) Normalized frequency distribution histogram versus CF calculated by considering all clear-sky MODIS measurements referring to Arnesano in 2006, 2007, and 2008. $\mathrm{N}$ represents the total number of used data points.
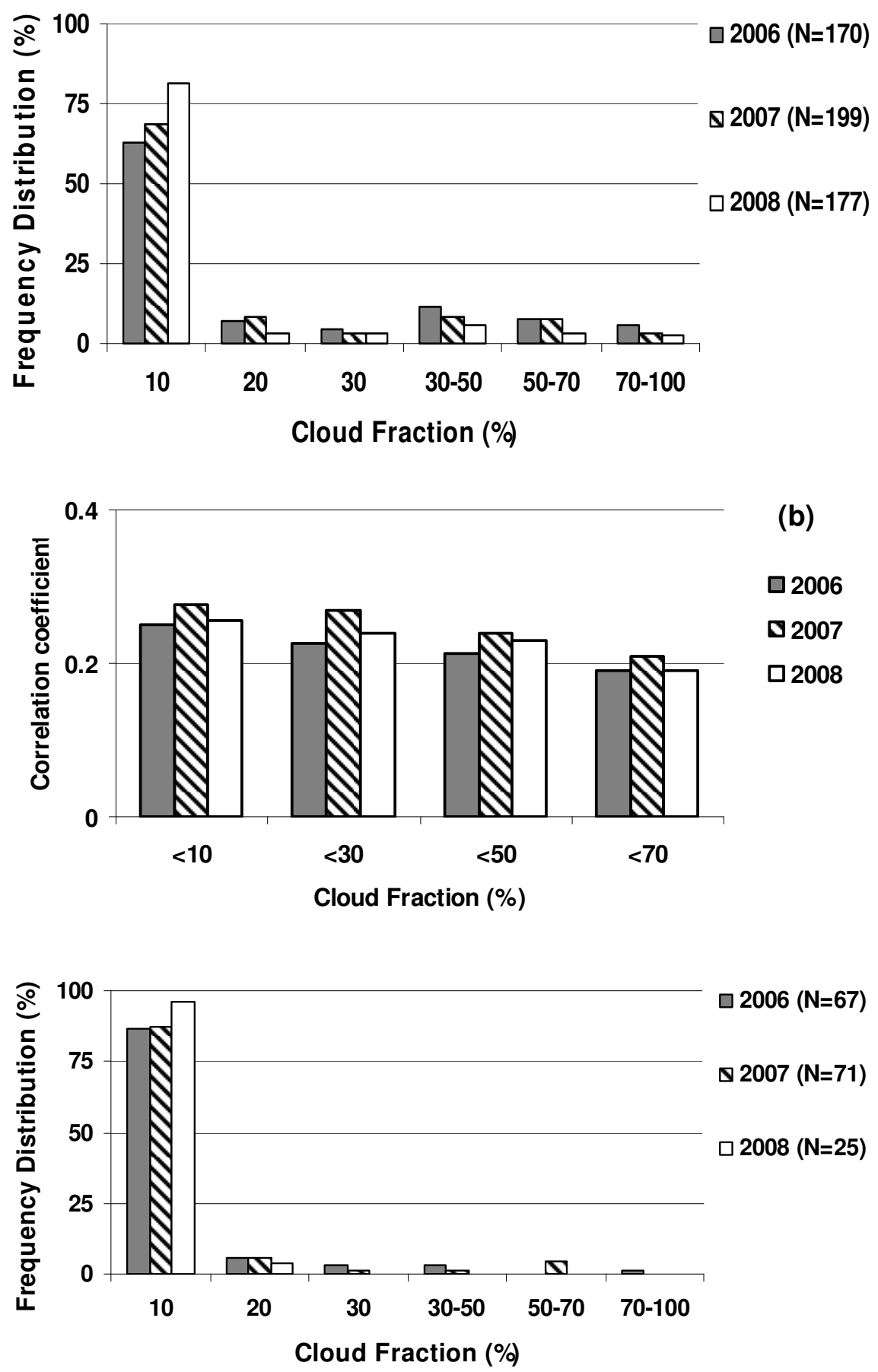


\subsection{Clear-Sky MODIS Measurements According to AERONET}

The availability of cloud cleared level 2 AERONET data collocated in time with Terra and Aqua overpasses is used in this study to select clear-sky MODIS AOTs, in accordance to [6]. Particularly, AERONET measurements from the sun/sky radiometer operating on the roof of the Physics Department of Universita' del Salento $\left(40.33^{\circ} \mathrm{N}, 18.10^{\circ} \mathrm{E}, 27 \mathrm{~m}\right.$ a.s.1.) in Lecce, which is few hundred meters away from the PM10 monitoring station of Arnesano, have been considered. AERONET is a federated international network of sun/sky radiometers established in 1993 which maintains more than 400 instruments worldwide [31]. Data are publicly available online in near real-time mode (http://aeronet.gsfc.nasa.gov). The CIMEL sun/sky radiometer measures direct sun radiance in eight spectral channels between 340 and $1,020 \mathrm{~nm}$. An automated cloud-screening and quality control procedure is applied to AOD direct-sun measurements [32]. The procedure consists of five parts: a data quality check, a triplet stability check, a diurnal stability check, a smoothness criteria check, and a three standard deviation criteria check [33]. The underlying principle of both the triplet stability and smoothness criteria checks is that the temporal variation of cloud optical depth is typically greater than the one of aerosol optical depth. In the triplet stability check, three measurements, each made 30 seconds apart, are performed. Then, it is assumed that the AOD in the total atmospheric column should vary by less than 0.02 within one triplet for all wavelengths if the atmosphere is to be considered stable and cloud free. The smoothness check computes the limiting root-mean-square of the second derivative of the optical depth with time. Because the second derivative reflects the variability tendency, the rootmean-square of the second derivative of the optical depth is very sensitive to the changes of AOD caused by clouds. In general, the average second derivative increases substantially when the data are cloud contaminated. However, since temporal variations of AOT are identified as cloud contamination, it must be noted that the AERONET cloud-screening procedure will screen some cases of variable aerosol plume. Conversely, stable uniform clouds will pass the algorithm threshold and be identified as cloud free.

MODIS measurements collocated in space and time with AERONET measurements have only been taken into account to select clear-sky MODIS-AOTs and evaluate the impact of cloud contamination on the PM-AOT correlation. Figures 5 and 6 (black dots) show the scatterplots of PM10 mass concentrations versus clear-sky MODIS-AOTs at Arnesano and Guagnano, respectively, in 2006, 2007, and 2008. The data reported in Figures 5 and 6 are summarized in Table 3, and show that the PM-AOT correlation becomes stronger by taking away cloud-contaminated MODIS-AOTs. This highlights the impact of cloud contamination on the PM-AOT relationship: regression line slopes which are quite affected by the adopted cloud screening procedure increase when the analysis is restricted to clear-sky days, intercept values that are less affected decrease. Selected clear-sky MODIS-AOTs have been grouped in different CF bins. The histogram of the normalized CF frequency distribution is shown in Figure $7 \mathrm{c}$ for the data set referring to Arnesano in 2006, 2007, and 2008. More than $87 \%$ of clear-sky AOTs have been retrieved from $20 \times 20 \mathrm{~km}^{2}$ boxes with a CF smaller than $10 \%$. This last result further indicates that cloud-contaminated MODIS-AOTs can lead to weaker PM-AOT relationships.

Table 3 reveals that the parameters of the PM-AOT relationship are quite sensitive to sampling year and monitoring site, even if the two sites of this study only are $20 \mathrm{~km}$ apart and both PM10 mass 
concentrations and MODIS-AOTs of the two sites are quite well correlated. However, multiyear data from different sites can allow a more general PM-AOT relationship to be achieved. The PM-AOT scatterplot (Figure 8), obtained by taking into accounts the three-year, clear-sky PM-AOT data points of Arnesano and Guagnano, is used to retrieve a mean PM10-AOT regression relationship for suburban sites of Southeastern Italy. In Figure 8, the solid line represents the linear regression line fitting the data points which is given by Equation (1). The linear correlation coefficient $(R=0.46)$ and total number of data points $(N=337)$ are also given in Figure 8.

$$
\left[\operatorname{PM} 10\left(\mu \mathrm{g} / \mathrm{m}^{3}\right)=25\left(\mu \mathrm{g} / \mathrm{m}^{3}\right)+65\left(\mu \mathrm{g} / \mathrm{m}^{3}\right) \times \text { AOT }\right]
$$

The average slope and intercept values given in Table 3 leads to an equation rather similar to Equation (1).

Equation (1) has been used to calculate PM10 mass concentrations at Arnesano and Guagnano in different years and to evaluate the accuracy of satellite estimated PM10 mass concentrations at the two selected sites of this study. Figure 9a shows the differences between measured and estimated PM10 mass concentrations versus time at Arnesano (open dots) and Guagnano (full dots). It is worth noting that rather few data points (37, 13, and 18, in 2006, 2007, and 2008, respectively) are, on average, available in AW months as a consequence of the larger presence of cloudy days. Dotted lines in Figure 9a represent \pm 1 standard deviation of PM10 mass concentration yearly means (Table 1). More than $80 \%$ of the differences are smaller than \pm 1 SD. This result is clearly revealed by Figure $9 \mathrm{~b}, \mathrm{c}$, showing the cumulative frequency distribution of absolute difference values at Arnesano and Guagnano, respectively. Yearly means \pm 1 SD of measured and satellite estimated PM10 mass concentrations are shown in the histogram of Figure 10a,b for Arnesano and Guagnano, respectively. Yearly-means of PM10 mass concentrations, estimated in accordance with Equation (1), agree reasonably well with corresponding values from PM10 measurements: the difference between estimated and measured yearly means is rather small in 2006 and 2007 and are $4 \mu \mathrm{g} / \mathrm{m}^{3}$ and $8 \mu \mathrm{g} / \mathrm{m}^{3}$ in 2008 at Arnesano and Guagnano, respectively. The decrease of PM10 mass concentrations from 2006 to 2008, is responsible for this last result. The dependence of the PM-AOT relationship on monitoring site (Table 3) also plays a role.

Table 3. Slope, intercept and linear correlation coefficient of the relationship between PM10 mass concentrations and clear-sky MODIS AOTs at Arnesano and Guagnano in 2006, 2007, and 2008.

\begin{tabular}{rccc|ccc}
\hline & \multicolumn{3}{c}{ ARNESANO } & \multicolumn{3}{c}{ GUAGNANO } \\
\hline & Slope & $\begin{array}{c}\text { Intercept } \\
\left(\boldsymbol{\mu g} / \mathbf{m}^{\mathbf{3}}\right)\end{array}$ & $\mathbf{R}$ & Slope & $\begin{array}{c}\text { Intercept } \\
\left(\boldsymbol{\mu g} / \mathbf{m}^{\mathbf{3}}\right)\end{array}$ & $\mathbf{R}$ \\
\hline $\mathbf{2 0 0 6}$ & 57 & 32 & 0.40 & 102 & 23 & 0.50 \\
$\mathbf{2 0 0 7}$ & 43 & 31 & 0.49 & 69 & 20 & 0.57 \\
$\mathbf{2 0 0 8}$ & 60 & 19 & 0.34 & 89 & 15 & 0.40 \\
\hline Mean & 53 & 27 & 0.41 & 87 & 19 & 0.49 \\
\hline
\end{tabular}


Figure 8. PM-AOT scatterplot obtained by taking into accounts all clear-sky PM-AOT data points retrieved at Arnesano and Guagnano over the different years. The solid line represents the linear regression line fitting the data points. Slope, intercept, correlation coefficient $(R)$, and total number of data points $(N)$ are also given.

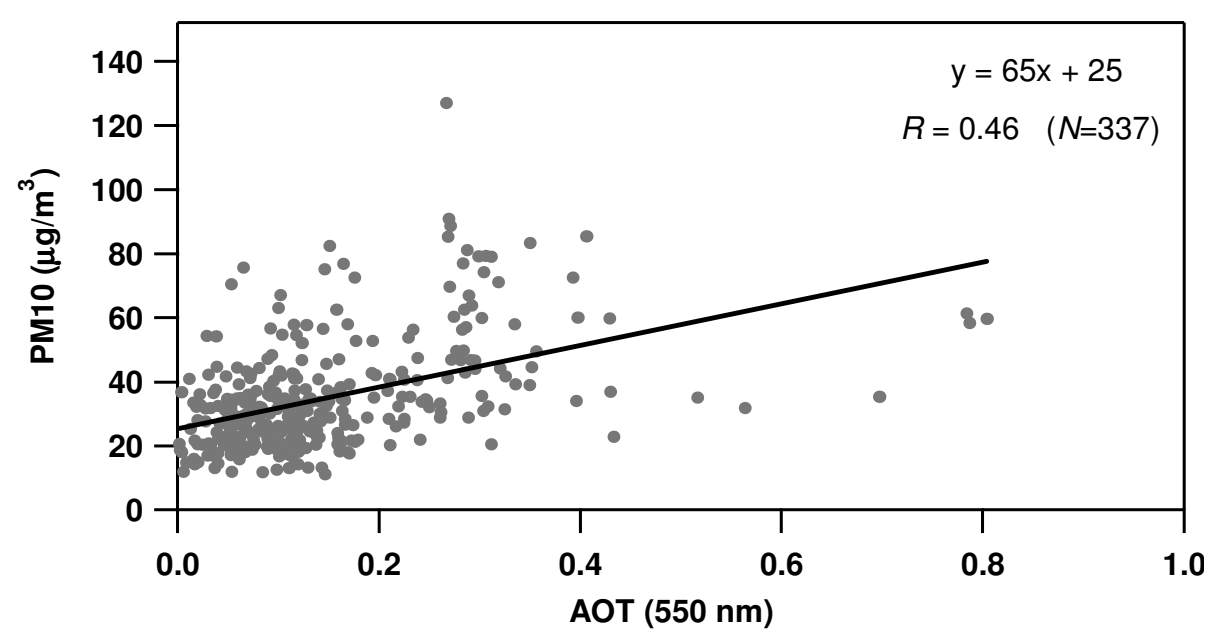

Figure 9. (a) Differences between measured and estimated PM10 mass concentrations in accordance with Equation (1) at Arnesano (open dots) and Guagnano (full dots) in 2006, 2007, and 2008. Dotted lines represent \pm 1 SD deviation of PM10 mass concentration yearly mean values. Cumulative frequency distribution of absolute difference values at (b) Arnesano and (c) Guagnano.

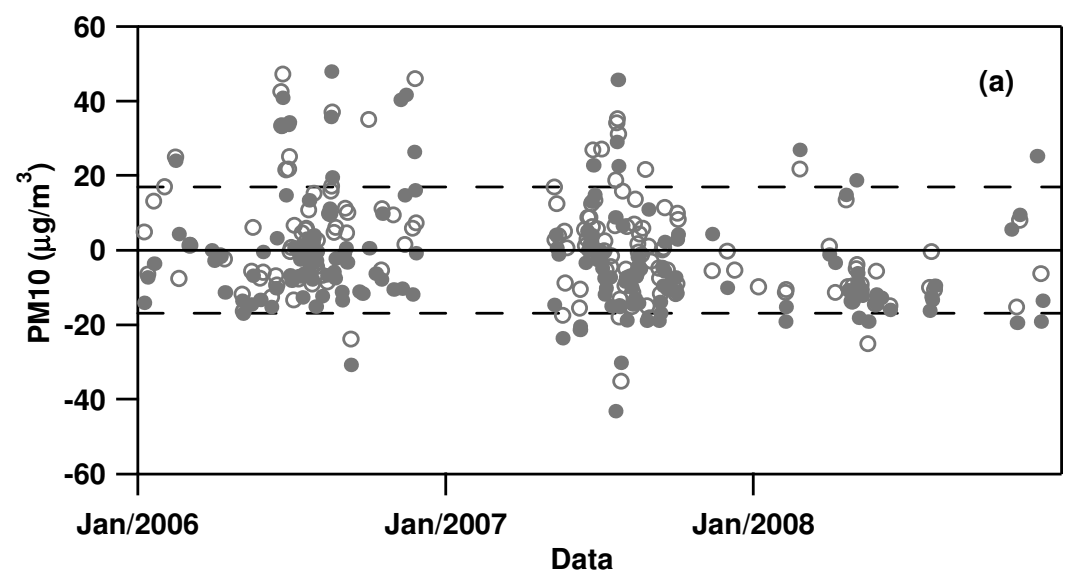

(b)
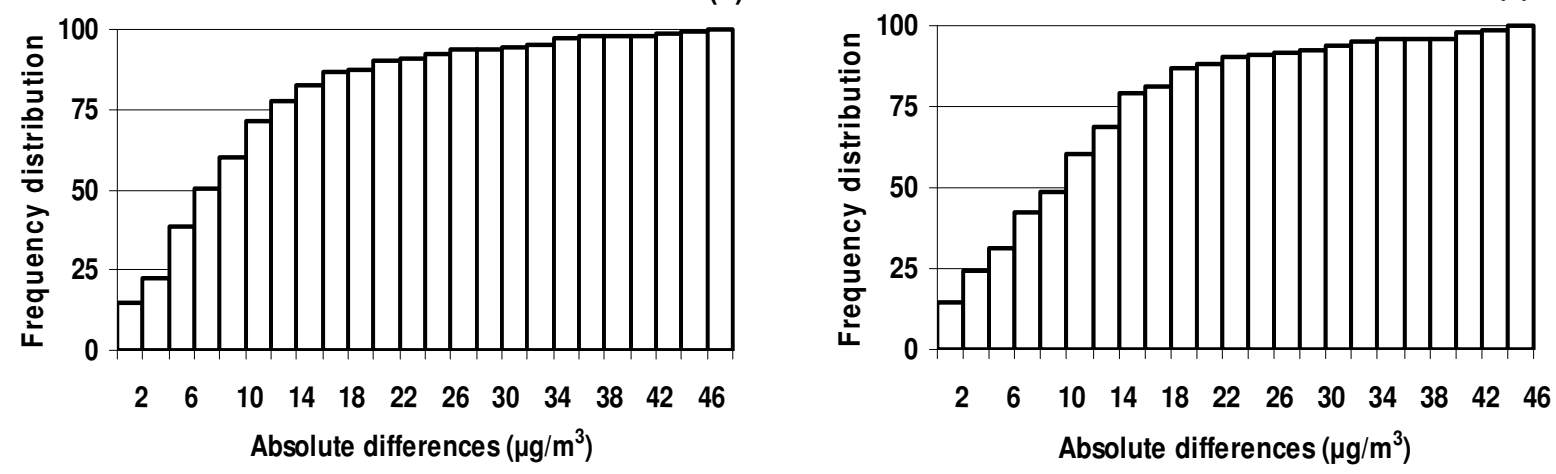
Figure 10. Yearly means $\pm 1 \mathrm{SD}$ of measured and satellite estimated PM10 mass concentrations by Equation (1) and Equation (2) at (a) Arnesano and (b) Guagnano.

$\square$ Mis $\Delta$ Equ.(1) $\square$ Equ.(2)

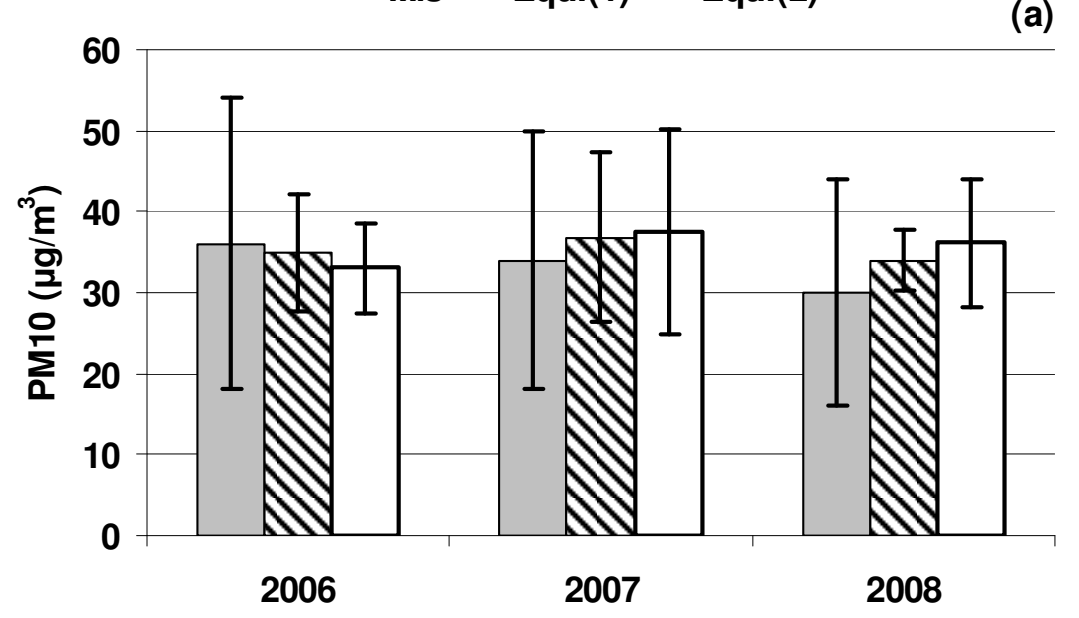

$\square$ Mis $\mathbf{D E q u . ( 1 ) ~} \square$ Equ.(2)

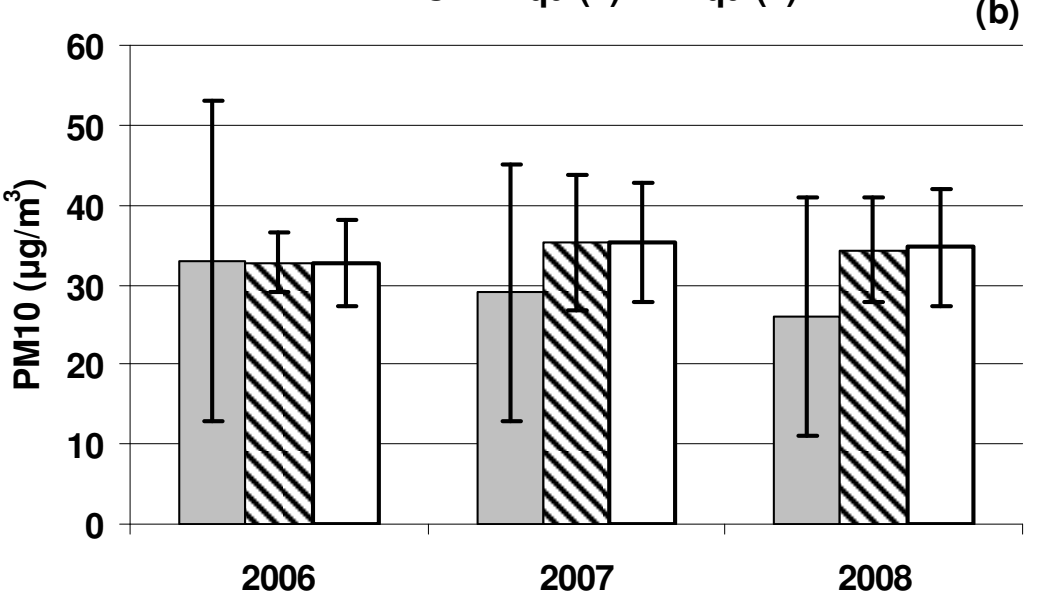

Smaller differences between measured and satellite estimated PM10 mass concentrations could be obtained by using a PM10-AOT relationship more suitable for each site (Table 3) and each year, however, the main goal of the paper was to get a more general PM10-AOT relationship for suburban sites of Southeastern Italy. AOT-PM relations reported in literature generally refer to PM2.5, since it is assumed that the coarse fraction contribute much less to the AOT than the fine fraction [2]. Stronger PM-AOT relations have usually been found when the PM2.5 fraction is accounted for [3]. Quite few AOT-PM10 relationships are reported in literature, even if the European air quality standard is at present set for 24-hour PM10 mass concentrations. Chu et al. [34] has provided some data for Northern Italy. In particular, they showed for the AERONET station at Ispra in Northern Italy, that time-series of AERONET-AOTs and 24-h average PM10 measurements correlate well $(R=0.77)$, for a period of several months in 2001 with stable meteorological conditions and that the AOT-PM10 relation was: PM10 $\left(\mu \mathrm{g} / \mathrm{m}^{3}\right)=8\left(\mu \mathrm{g} / \mathrm{m}^{3}\right)+55\left(\mu \mathrm{g} / \mathrm{m}^{3}\right) \times$ AOT. AOTs are on average larger at Ispra than over Southeastern Italy and PM10 mass concentrations are characterized by a marked seasonal dependence with quite large (small) values in AW (SS) [9]. 


\section{Sensitivity Studies}

The accuracy of satellite estimated PM10 mass concentrations depends on the robustness of the regression relationship between AOT and PM10 mass, which can depend on the accuracy of retrieved AOTs and other factors such as local meteorological conditions [3]. In fact, the AOT is a quantitative measure of the integrated columnar aerosol load, from the ground up to the top of the atmosphere, while the PM concentration is a quantitative measure of the particulate mass concentration at the surface. Therefore, the relationship between ground mass concentrations and AOTs is expected to be dependent on meteorological parameters. The vertical distribution of aerosols may also affect the PM-AOT relationship: elevated aerosol layers originated from remote sources contribute to the AOT, but may poorly affect mass concentrations at the ground [3]. The role of the mixing layer height and ground wind-speed on the PM10-AOT relationship is investigated in this section in order to get a better understanding of the main parameters affecting the strength of the PM10-AOT relationship and to improve the overall accuracy of PM10 mass estimations from satellite observations. A simple analysis to infer the impact of large Sahara dust outbreaks to the strength of the PM10-AOT relationship is reported in Section 4.3.

\subsection{Mixing Layer Height's Role}

The mixing layer height (MLH) is a key parameter for the assessment of pollution: it determines the volume in which turbulence is active and into which aerosols, emitted near the surface, are dispersed. When the MLH is low almost all aerosols are present near the surface and the satellite will observe almost the same amount of aerosol mass as observed by ground instruments. Conversely, in the case of large MLHs, satellites still observe the same aerosol amount (as satellites measure columnar loading), but ground PM samplers observe smaller particle mass concentrations near the ground. Hence, the PM-AOT relationship can strongly depend on the MLH in the atmosphere.

We have used the Lagrangian HYSPLIT 4 model [35], widely applied in many studies, for the estimation of the mixing layer height during MODIS measurements. The HYSPLIT model assumes a well mixed layer in which pollutant transport and dispersion take place and calculates the vertical extent of the mixing layer from the potential temperature. HYSPLIT MLH values are provided every three hours. MLH values provided from 9 until 15 UTC have been used in this study to calculate the mean MLH (Hmix) during the Terra and Aqua overpass times. Figures $2 \mathrm{c}$ and $3 \mathrm{c}$ show the Hmix time evolution at the two selected monitoring sites from 2006 up until the end of 2008. Grey lines represent daily mean values of the 9-15 Universal Time MLH values. In each plot, black lines represent monthly averaged Hmix values. Minimum (Min), maximum (Max), yearly, autumn-winter (AW), and springsummer (SS) mean values of Hmix with \pm 1 SD are reported in Table 4 for both sites. Figures $2 \mathrm{c}$ and $3 \mathrm{c}$ show that Hmix spans the $0.07-2.5 \mathrm{~km}$ range. In addition, Figures $2 \mathrm{c}-3 \mathrm{c}$ and Table 4 reveal that Hmix monthly means span the $0.66-0.72 \mathrm{~km}$ and the $0.38-0.60 \mathrm{~km}$ range in AW and SS, respectively. Hence, AW Hmix mean values are, on average, larger than SS mean values, in contrary to what it is expected. The anomalous behavior of the MLH seasonal evolution revealed by HYSPLIT data is in satisfactory accordance with experimental based MLH measurements performed over Southern-East Italy [13]. Measurements by a lidar system operating at the Physics Department of the Universita' del Salento 
(Lecce, Italy) and radio sounding measurements performed at the meteorological station of Brindisi [36] situated on the coast, $40 \mathrm{~km}$ away from the lidar site, have been used by [13] to investigate the seasonal evolution of the MLH from May 2000 to August 2002. It is shown by [13] that the smaller MLHs generally found in SS can be explained in terms of the suppression of the mixing layer height growth caused by the advection of marine air. A MLH seasonal evolution similar to that of Lecce has also been found at Athens (Greece) and Barcelona (Spain) [37].

Table 4. Yearly means, minimum (Min), maximum (Max), autumn-winter (AW), and spring-summer (SS) mean values $\pm 1 \mathrm{SD}$ deviation of mixing layer height mean values (Hmix (m)) at Arnesano and Guagnano in 2006, 2007, and 2008.

\begin{tabular}{c|ccc|ccc}
\hline & \multicolumn{3}{c}{ ARNESANO } & \multicolumn{3}{c}{ GUAGNANO } \\
\hline & $\mathbf{2 0 0 6}$ & $\mathbf{2 0 0 7}$ & $\mathbf{2 0 0 8}$ & $\mathbf{2 0 0 6}$ & $\mathbf{2 0 0 7}$ & $\mathbf{2 0 0 8}$ \\
\hline Yearly means (m) & $615 \pm 335$ & $488 \pm 381$ & $489 \pm 338$ & $642 \pm 336$ & $532 \pm 396$ & $507 \pm 344$ \\
Min - Max (m) & $148-1466$ & $73-2527$ & $77-1923$ & $175-1553$ & $73-2527$ & $77-1923$ \\
AW (m) & $669 \pm 352$ & $690 \pm 434$ & $657 \pm 367$ & $706 \pm 351$ & $710 \pm 426$ & $717 \pm 367$ \\
SS (m) & $583 \pm 322$ & $390 \pm 307$ & $394 \pm 280$ & $603 \pm 320$ & $424 \pm 334$ & $382 \pm 261$ \\
\hline
\end{tabular}

Figure 11a shows, as an example, the scatterplot of PM10 mass concentrations versus Hmix values for the site of Arnesano and 2006-year data and reveals the sensitivity of PM10 mass concentrations to Hmix values: higher PM10 mass concentrations are found at lower Hmix values. Hence, the PM-AOT relationship is expected to depend on the AOT/Hmix ratio. Figures $12 \mathrm{a}-\mathrm{c}$ and $13 \mathrm{a}-\mathrm{c}$ show the scatterplot of PM10 mass concentrations versus clear-sky AOT/Hmix values at Arnesano and Guagnano, respectively, in 2006, 2007, and 2008. In each plot, solid lines represent the linear regression line fitting the data points. The comparison of Figures 5 and 6 to Figures 12 and 13, respectively, reveals that $R$ values increase from 12 to $53 \%$ at Arnesano and from 16 to $24 \%$ at Guagnano, when PM10 mass concentrations are correlated to clear-sky AOT/Hmix values. These last results indicate that the PM-AOT correlation becomes stronger over Southern-East Italy when the AOT is divided by the mixing layer height, in accordance with results by [4]. They found that correlation coefficients of daily-PM10-AOT relationships increase by $29 \%$ and $100 \%$ for background and traffic sites, respectively, and decrease by $49 \%$ for rural background sites, when the MODIS-AOT is normalized by the MLH. The analysis of the relationship between MODIS-AOT and PM10 performed by [3] in the Taiwan area from 2006 to 2008 has revealed that correlation coefficients increase less than $10 \%$ when MODIS-AOTs are normalized by the MLH. 
Figure 11. Scatterplot of PM10 mass concentrations versus (a) mixing layer height mean values (Hmix) and (b) wind speed mean values (WSav) for Arnesano and 2006-year data.
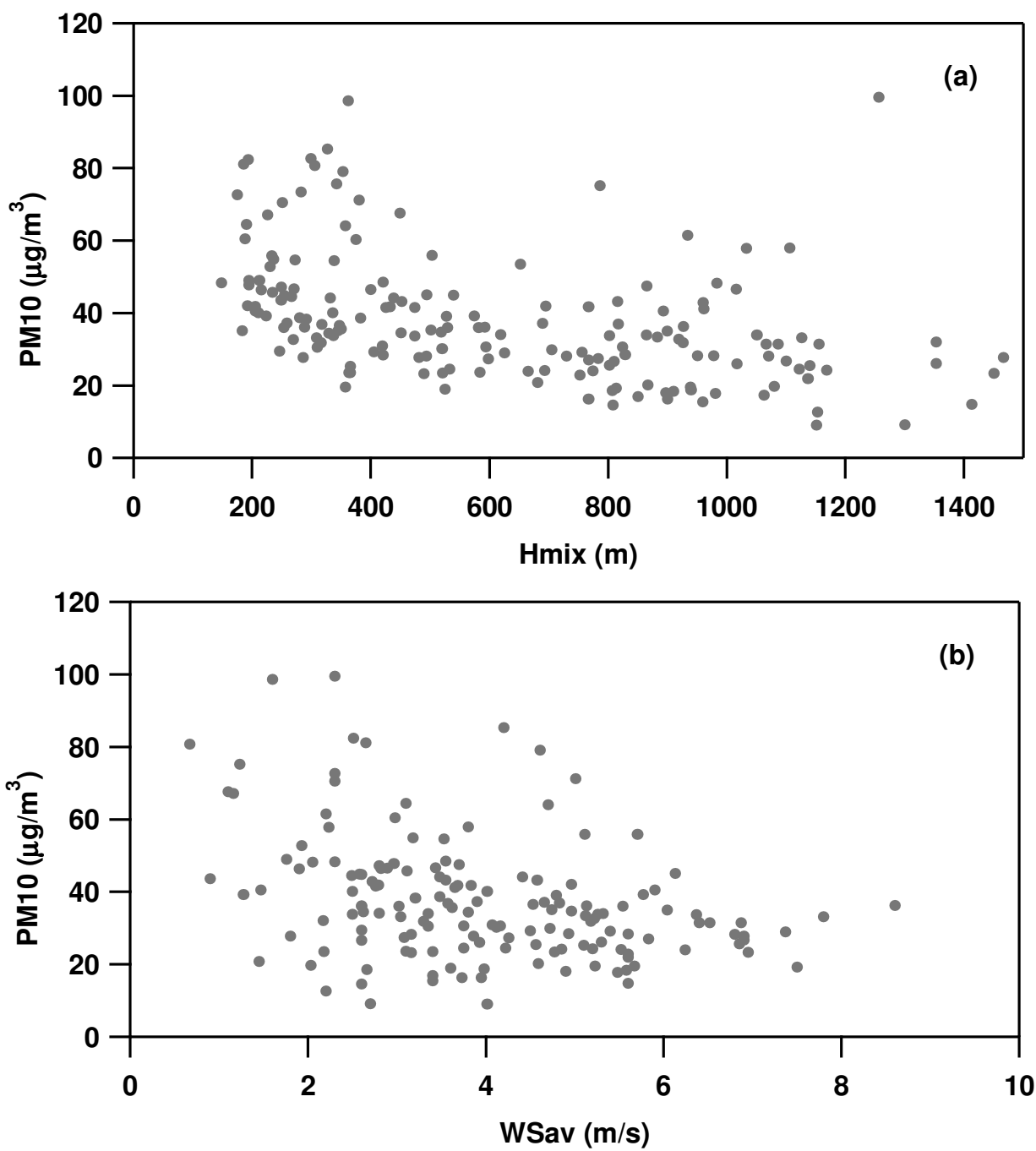

Figure 12. Scatterplot of Arnesano-PM10 mass concentrations versus clear-sky AOTs/Hmix values for (a) 2006, (b) 2007, and (c) 2008. Slope, intercept and linear correlation coefficient $(R)$ are also given in each plot in addition to the total number of data points $(N)$.
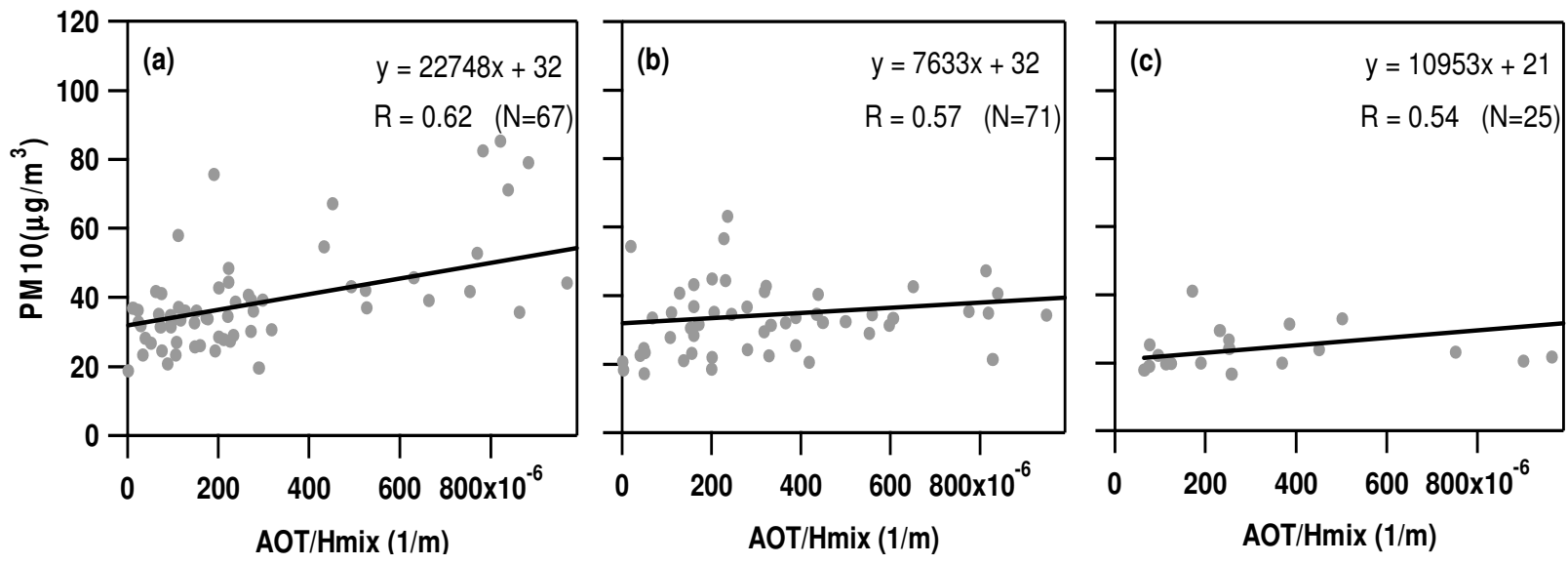
Figure 13. Scatterplot of Guagnano-PM10 mass concentrations versus clear-sky AOTs/Hmix values for (a) 2006, (b) 2007, and (c) 2008. Slope, intercept and linear correlation coefficient $(R)$ are also given in each plot in addition to the total number of data points $(N)$.
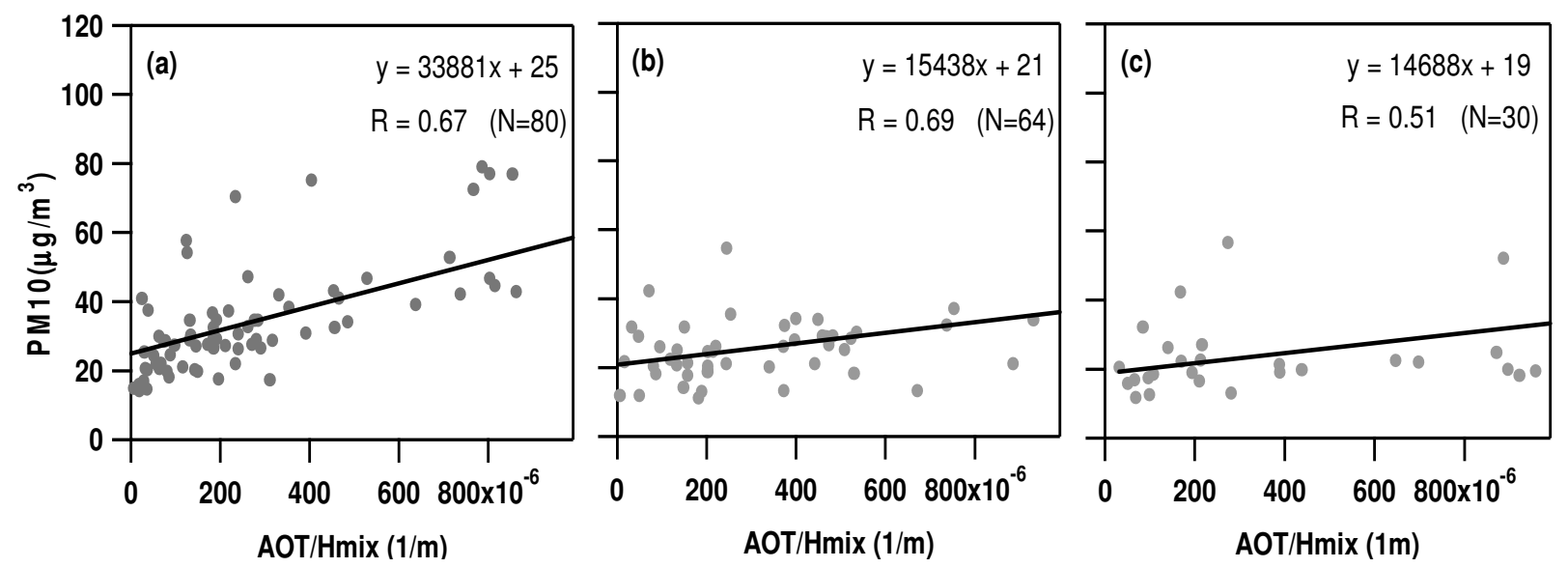

\subsection{Wind Speed's Role}

In addition to the mixing layer height, surface wind speed also plays a crucial role in aerosol generation and dispersion. To investigate the sensitivity of the PM-AOT relationship to wind speed (WS), WS measurements performed at about $10 \mathrm{~m}$ from the ground at the Meteorological Station of the Universita' del Salento, which is few hundred meters away from the PM monitoring site of Arnesano, were used in this study. Wind speed measurements are provided every 30 minutes and the values from 9 until 15 Universal Time have been used in this study to calculate a mean WS value (WSav) for the time-interval during which Terra and Aqua overpass Southeastern Italy. Figure 2d shows the WSav time evolution from 2006 to 2008. The grey line represents daily mean values of the 9-15 Universal Time wind speed values (WSav). The black line represents monthly averaged WSav values. Minimum (Min), maximum (Max), yearly, autumn-winter (AW), and spring-summer (SS) mean values of WSav with $\pm 1 \mathrm{SD}$ are reported in Table 5. Daily WSav values span the $0.7-11.3 \mathrm{~m} / \mathrm{s}$ range and yearly means are equal to $4 \pm 2 \mathrm{~m} / \mathrm{s}$. The sensitivity of PM10 mass concentrations to WSav values is revealed by Figure 11b showing, as an example, the scatterplot of PM10 mass concentrations versus WSav values for the site of Arnesano in 2006. From Figure 11b, we observe that PM10 mass concentrations decrease as the wind speeds increase.

Table 5. Yearly means, minimum (Min), maximum (Max), autumn-winter (AW), and spring-summer (SS) mean values $\pm 1 \mathrm{SD}$ deviation of wind speed mean values (WSav $(\mathrm{m} / \mathrm{s}))$ at Arnesano in 2006, 2007, and 2008.

\begin{tabular}{c|ccc}
\hline \multicolumn{4}{c}{ ARNESANO } \\
\hline & $\mathbf{2 0 0 6}$ & $\mathbf{2 0 0 7}$ & $\mathbf{2 0 0 8}$ \\
Yearly means (m/s) & $4.0 \pm 2.0$ & $4.0 \pm 2.0$ & $4.0 \pm 2.0$ \\
Min - Max (m/s) & $0.7-8.6$ & $0.7-11.3$ & $1.0-9.0$ \\
AW (m/s) & $3.5 \pm 2.0$ & $3.6 \pm 2.0$ & $3.7 \pm 2.0$ \\
SS (m/s) & $4.0 \pm 1.5$ & $4.0 \pm 1.5$ & $4.4 \pm 1.5$ \\
\hline
\end{tabular}


Figure 14a-c shows the scatterplot of Arnesano-PM10 mass concentrations versus clear-sky AOTs divided by the (WSav $\times$ Hmix) product in 2006, 2007, and 2008, respectively. The product of the MLH and the wind speed represents the so-called ventilation index: a parameter that provides a measure of how well pollutants are dispersed into the atmosphere [38]. In each plot of Figure 14a-c, solid lines represent the linear regression line fitting the data points. Figure 14 reveals that the inclusion of WSav makes the PM-AOT relationship a bit stronger. Similar results were also obtained at Guagnano. The scatterplots of Guagnano-PM10 mass concentrations versus clear-sky AOT/(WSav $\times$ Hmix) are given in Figure 15a-c, in 2006, 2007, and 2008 respectively. Wind speed measurements performed at the Meteorological Station of the Universita' del Salento have also been used for Guagnano since local WSs were not available. The sensitivity of correlation coefficient and regression line parameters to site location and year becomes stronger when the AOT is normalized by the (WSav $\times$ Hmix) product. Figure 16 shows the mean scatterplot of PM10 versus AOT/(WSav $\times$ Hmix) obtained by including three years of Arnesano and Guagnano data points. The solid line represents in Figure 16 the linear regression line fitting the data points that is given by Equation (2). Linear correlation coefficient $(R=0.50)$ and total number of data points $(N=326)$ are also given in Figure 16.

$$
\left[\operatorname{PM} 10\left(\mu \mathrm{g} / \mathrm{m}^{3}\right)=29\left(\mu \mathrm{g} / \mathrm{m}^{3}\right)+32,770(\mu \mathrm{g} / \mathrm{sec} \mathrm{m}) \times \text { AOT } /(\mathrm{WSav} \times \mathrm{Hmix})\right]
$$

Equation (2) has also been used to calculate PM10 mass concentrations at Arnesano and Guagnano in different years. Figure 17a shows the differences between measured and estimated PM10 mass concentrations at Arnesano (open dots) and Guagnano (full dots) by considering the three year data set. Dotted lines in Figure 17a represent \pm 1 SD of PM10 mass concentration yearly means (Table 1). The cumulative frequency distribution of difference absolute values related to Arnesano and Guagnano are plotted in Figure 17b,c, respectively. Yearly means \pm 1 SD of PM10 mass concentrations calculated by Equation (2) are plotted in Figure 10a and b for Arnesano and Guagnano, respectively. The comparison of Figure 9 and Figure 17 reveals that Equation (2) does not allow improvement of the accuracy of satellite estimated PM10 mass concentrations at the two selected sites. This last result is probably due to the fact that the linear correlation coefficient of the scatterplot shown in Figure 16 is less than 10\% larger than that of Figure 8. Hence, PM-AOT relationships that account for meteorological parameters and/or aerosol properties are only useful to obtain better PM satellite estimates if they allow obtaining rather strong PM-AOT correlations. Several papers [3,4] have also revealed that usually, the AOT normalization by the MLH, the aerosol layer height, and/or the function describing the increases of the aerosol extinction cross section with relative humidity, allows increasing correlation coefficients of PM-AOT relationships only of a few percent. 
Figure 14. Scatterplot of Arnesano-PM10 mass concentrations versus clear-sky AOTs divided by the (WSav $\times$ Hmix) product for (a) 2006, (b) 2007, and (c) 2008. Slope, intercept and linear correlation coefficient $(R)$ are also given in each plot in addition to the total number of data points $(N)$.
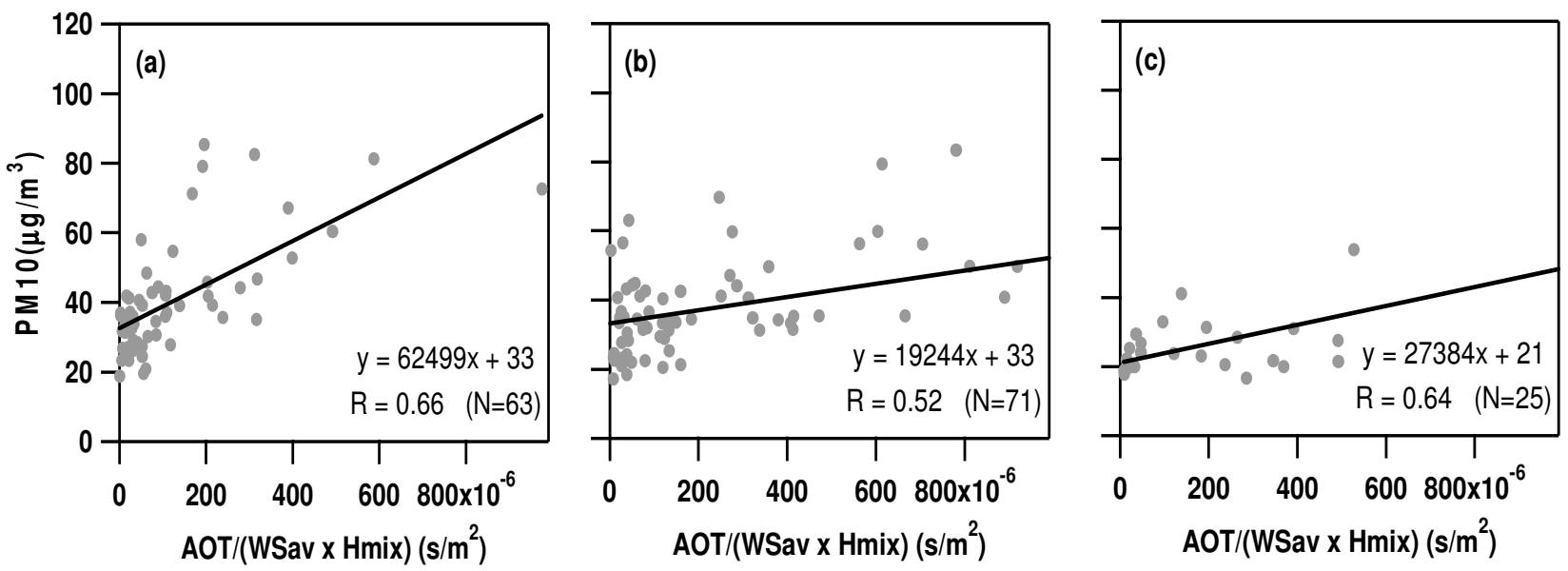

Figure 15. Scatterplot of Guagnano-PM10 mass concentrations versus clear-sky AOTs divided by the (WSav $\times$ Hmix) product for (a) 2006, (b) 2007, and (c) 2008. Slope, intercept and linear correlation coefficient $(R)$ are also given in each plot in addition to the total number of data points $(N)$.
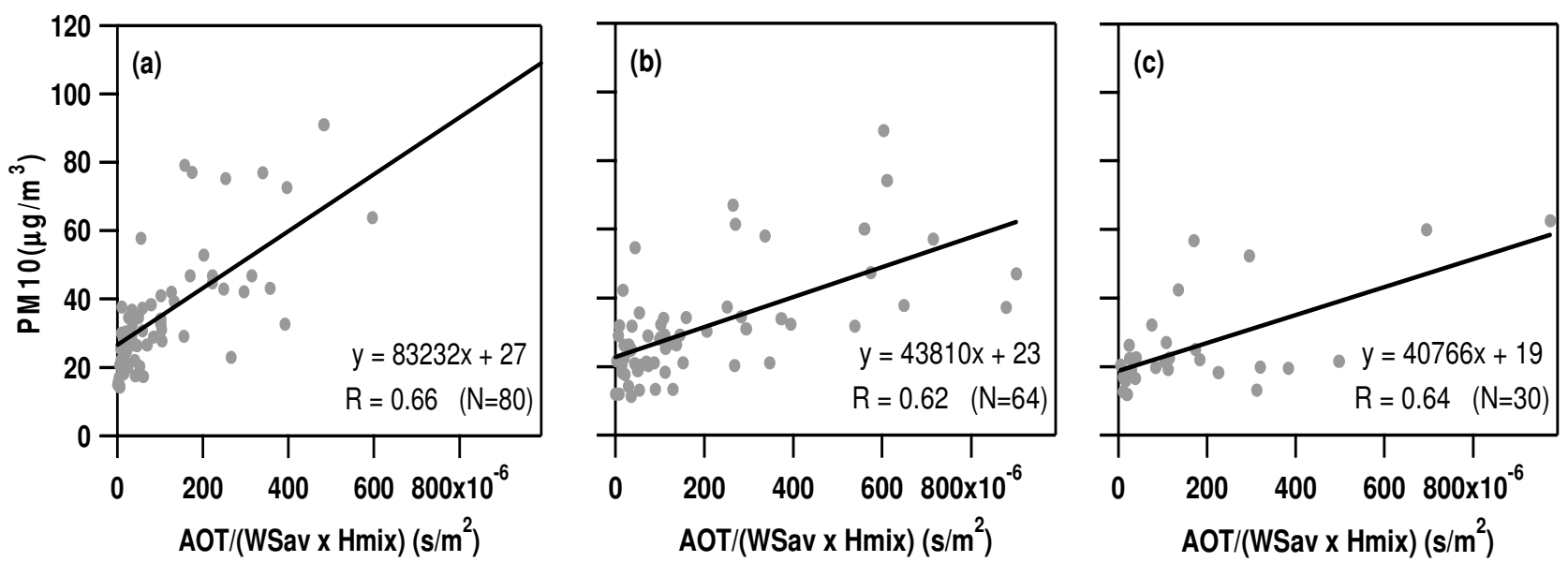
Figure 16. Scatterplot of PM10 versus AOT/(WSav $\times$ Hmix) by including the Arnesano and Guagnano data points referring to different years. The solid line represents the linear regression line fitting the data points. Slope, intercept, correlation coefficient $(R)$, and total number of data points $(N)$ are also given.

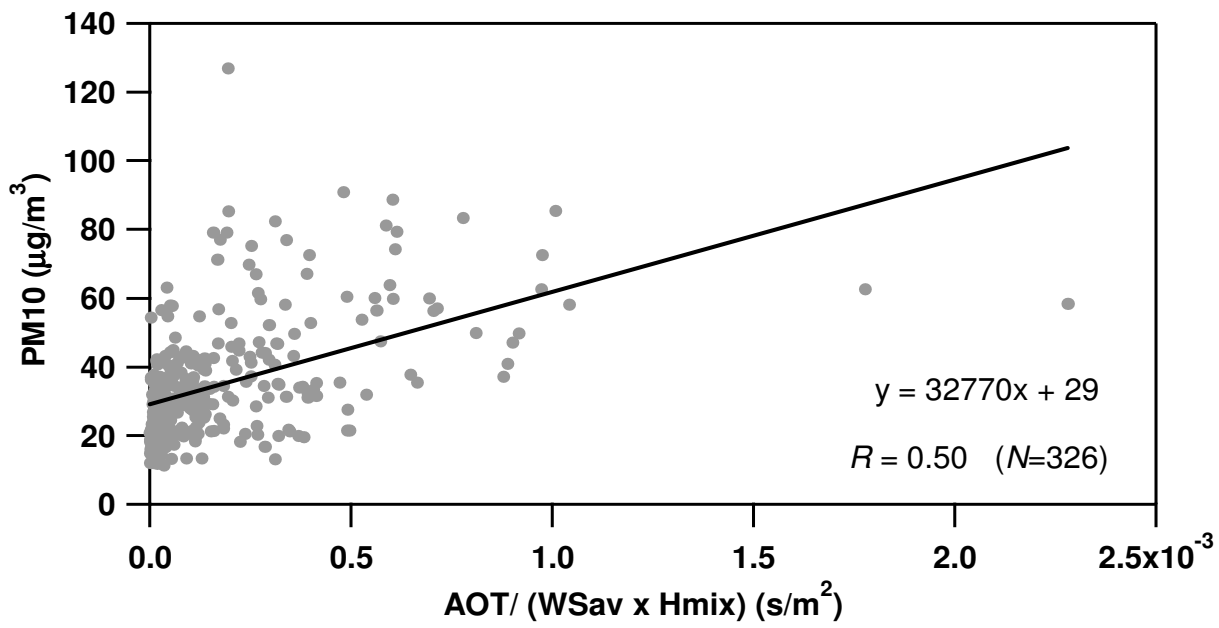

Figure 17. (a) Differences between measured and estimated PM10 mass concentrations in accordance with Equation (2) for Arnesano (open dots) and Guagnano (full dots) in 2006, 2007, and 2008. Dotted lines represent \pm 1 SD deviation of PM10 mass concentration yearly means. Cumulative frequency distribution of absolute differences at (b) Arnesano and (c) Guagnano.

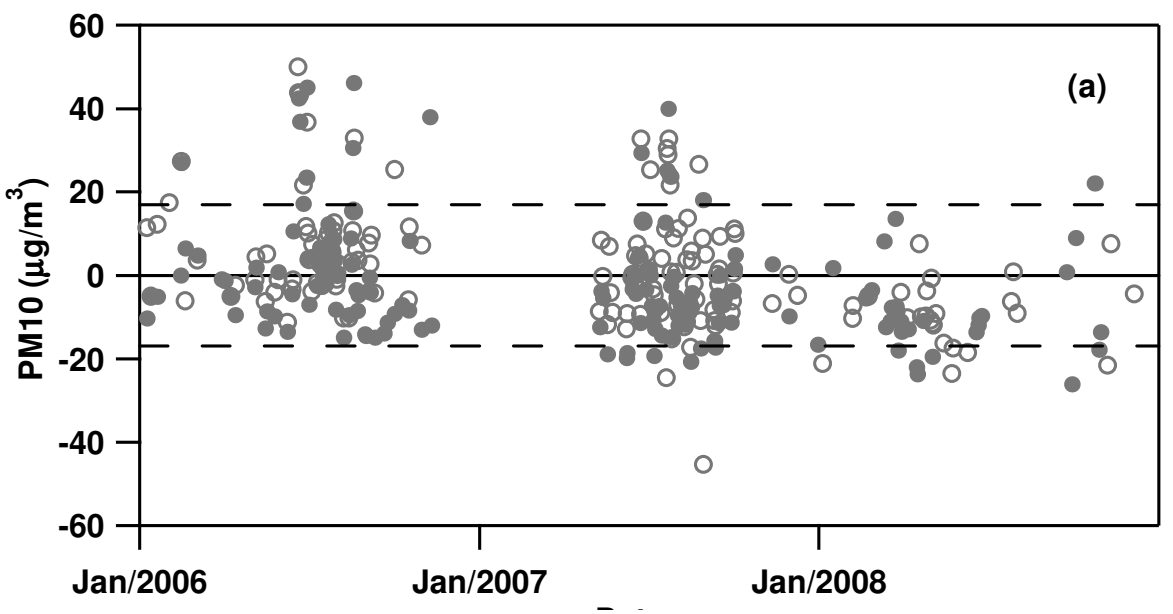

(b)

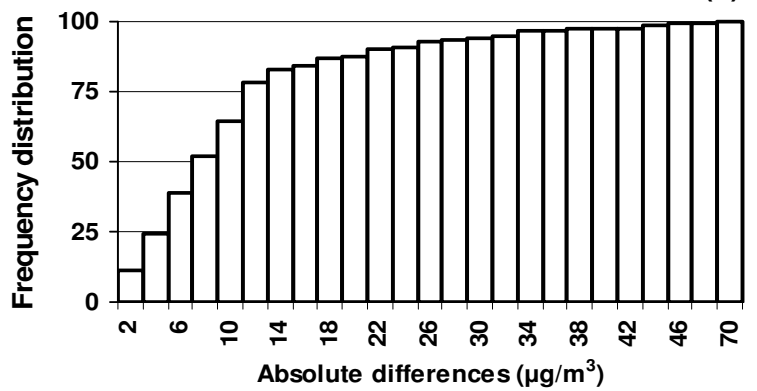

(c)

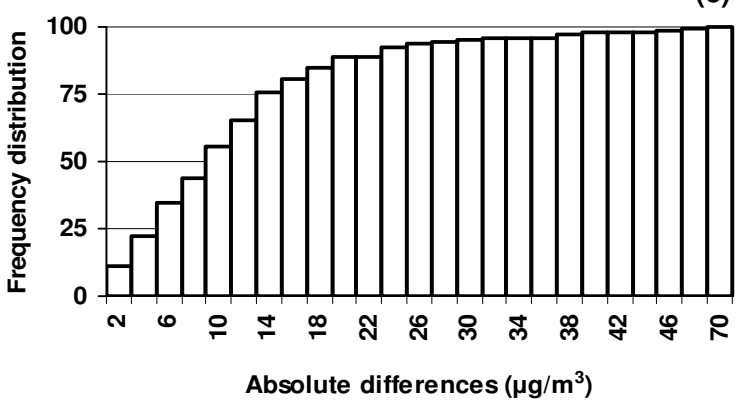




\subsection{Impact of Dust Particles}

The advection above the boundary layer of long range transported air masses, such as those due to Sahara dust plumes is expected to impact the AOT-PM relationship. Columnar aerosol properties retrieved from Lecce University sunphotometer measurements have been used in this study to infer the advection of Sahara dust particles over Southeastern Italy and the analysis has been restricted to days characterized by large AOTs $(\geq 4)$ and relatively small PM10 mass concentrations $\left(\leq 60 \mu \mathrm{gr} / \mathrm{m}^{3}\right)$. Indeed, the AERONET Angstrom coefficient $(\AA)$, computed from AOT values at $440 \mathrm{~nm}$ and $870 \mathrm{~nm}$, has been used to characterize columnar aerosol properties over Southeastern Italy. Typical $\AA$ values range from 1.5 for aerosol dominated by accumulation mode particles, to nearly zero for large dust particles [8,31]. Nine data points are characterized by AOT $\geq 0.4$ and PM10 mass concentration $\leq 60 \mu \mathrm{gr} / \mathrm{m}^{3}$, in accordance with the scatterplot of Figure 8 . The data points are listed in Table 6 where AOT, mass concentration, and $\AA$ values are also reported. Measurements performed on September 11, 2006 are mainly affected by Sahara dust in accordance with Table 6. Analytical back trajectories [39] and MODIS true colour images [40] support this conclusion. The large $\AA$ values characterizing the other measurement days of Table 6 indicate that the rather high AOTs retrieved from MODIS measurements are mainly due to anthropogenic fine mode particles. In addition to $\AA$ values, analytical back trajectories by AERONET and MODIS true color images have been used to identify aerosol source regions of July and August, 2007 days. We have found that the rather high AOTs monitored on July 2007 were mainly due to the presence of smoke particles generated by forest fires occurred over Southestern Italy (Gargano aera) about $400 \mathrm{~km}$ away from Arnesano and Guagnano, respectively. The large AOT retrieved on August 31, 2007 is instead mainly due to smoke from the Greek fires in August 2007 [41]. Therefore, the rather simple analysis of this section indicates that slope and correlation coefficient of the regression line of Figure 8 are not significantly affected by large AOT values $(\geq 0.4)$ retrieved during the advection of Sahara dust particles.

Table 6. PM mass concentration, AOT, and Angstrom coefficient $(\AA)$ values of the data points with AOT $\geq 0.4$ and PM10 mass concentrations $\leq 60 \mu \mathrm{gr} / \mathrm{m}^{3}$.

\begin{tabular}{cccc}
\hline $\begin{array}{c}\text { Date } \\
\mathbf{d d} / \mathbf{m m} / \mathbf{y y}\end{array}$ & $\begin{array}{c}\mathbf{P M} \\
\left(\boldsymbol{\mu g} / \mathbf{m}^{\mathbf{3}}\right)\end{array}$ & $\begin{array}{c}\text { AOD } \\
(\mathbf{5 5 0} \mathbf{~ n m})\end{array}$ & $\begin{array}{c}\AA \\
\mathbf{( 4 4 0 - 8 7 0} \mathbf{~ n m})\end{array}$ \\
\hline $11 / 09 / 2006$ & 35.1 & 0.52 & 0.48 \\
$11 / 09 / 2006$ & 22.8 & 0.43 & 0.48 \\
$06 / 05 / 2006$ & 36.9 & 0.43 & 1.69 \\
$21 / 07 / 2007$ & 59.8 & 0.43 & 1.80 \\
$26 / 07 / 2007$ & 59.6 & 0.80 & 1.95 \\
$26 / 07 / 2007$ & 61.5 & 0.78 & 1.95 \\
$28 / 07 / 2007$ & 35.5 & 0.70 & 1.91 \\
$28 / 07 / 2007$ & 31.8 & 0.56 & 1.91 \\
$31 / 08 / 2007$ & 58.3 & 0.78 & 1.18 \\
\hline
\end{tabular}




\section{Summary and Conclusion}

24-hour averaged PM10 mass concentrations and MODIS-AOTs collocated in space have been used to explore the use of MODIS-AOTs for air quality predictions over Southeastern Italy and to contribute to the understanding of the PM10-AOT relationship since European air quality standards are now set for 24 hour PM10 mass concentrations. The study has been restricted to two suburban sites: the PM monitoring is usually less frequent or missing at suburban sites. The two sites of this study are only 20 $\mathrm{km}$ apart to better test the sensitivity of the PM10-AOT relationship on site location. The statistical analysis of PM10 mass concentrations has revealed a small seasonal dependence: AW-mass concentrations are slightly larger than SS mean values at both sites. The small dependence on seasons of PM10 mass concentrations is typically found over Southeastern Italy and it is probably due to the suppressed evolution with seasons of the planetary boundary layer height, as a consequence of sea breeze effects. In fact, the two selected sites are characterized by an unusual seasonal evolution of the MLH: autumn-winter MLH mean values are on average larger than spring-summer mean values. The Lagrangian HYSPLIT 4 model, widely applied in many studies for the estimation of the mixing layer height, has been used in our study. The statistical analysis of MODIS-AOTs based on Terra- and Aqua-MODIS measurements has revealed that AW-AOTs are smaller than SS-AOTs at both sites despite the seasonal dependence of PM10 mass concentrations.

A first assessment of the regression relationship between daily averaged PM10 mass concentrations and MODIS-AOTs has led to a weak PM-AOT relationship $(0.20 \leq R \leq 0.35)$, partially due to the presence of cloud-contaminated AOTs: we have found that correlation coefficients on average increase as MODIS cloud fractions decrease. The cloud-screening procedure adopted within AERONET has been used to obtain a better selection of clear-sky MODIS measurements and hence stronger $(0.34 \leq R \leq 0.57)$ PM-AOT relationships. Hence, the effect on the PM-AOT relationship of cloud-contaminated MODISAOTs has been demonstrated. The mean empirical relation we have found by taking into account three years of clear-sky data points has been used to calculate PM10 mass concentrations over different years and evaluate the accuracy of satellite estimated PM10 mass concentrations at the two suburban sites of this study. We have found that $80 \%$ of differences between measured and calculated PM10 mass concentrations are within \pm 1 SD of mass concentration yearly means. In particular, yearly-means of PM10 mass concentrations estimated in accordance with Equation (1) agree reasonably well with corresponding values from PM10 measurements: the differences between estimated and measured yearly means are rather small in 2006 and 2007 and equal $4 \mu \mathrm{g} / \mathrm{m}^{3}$ at Arnesano and $8 \mu \mathrm{g} / \mathrm{m}^{3}$ at Guagnano in 2008. The rather small amount of available clear-sky AOTs in 2008 and the PM10 mass concentration decrease from 2006 to 2008 are mainly responsible for the larger differences between measured and estimated PM mass concentrations found in 2008.

The role of the mixing layer height and ground wind-speed on the PM10-AOT relationship has also been explored. We have found that the PM-AOT relationship becomes stronger $(0.52 \leq R \leq 0.65)$ when the AOT is divided by the mixing layer height and ground wind-speed. However, the empirical relationship that also accounts for mixing layer height and ground wind-speed, does not improve satellite estimated PM10 mass concentrations. The small effect on the PM-AOT relationship (small increase of correlation coefficients), when we account for mixing layer height and ground wind-speed, is probably responsible for these last results. Hence, a rather large increase of $R$ is required to 
significantly improve satellite estimated PM10 mass concentrations. Several papers have also revealed that $R$ values usually increase only a few percent when the AOT is normalized by meteorological parameters and/or factors that account for aerosol properties, in accordance with our results. Our results have also highlighted that the PM-AOT relationship for suburban sites can vary within a few tens of kilometers and can be affected by sampling year. In conclusion, our results, which are in accordance with those provided for different sites worldwide, show the potential of MODIS data for evaluating air quality in suburban sites of Southeastern Italy. We continue to investigate the effects of longer study periods on the PM-AOT relationship and to test if the empirical relation found can be applied to other suburban sites of Southeastern Italy and of the Central Mediterranean where PM10 mass concentrations and MODIS AOTs follow a seasonal trend similar to that observed in the two sites of this study.

\section{Acknowledgements}

This research has been supported by Progetto Strategico SIMPA financed by Regione Puglia and A. Dinoi has carried out this work with the support of a post-doc fellowship. We would like to thank the Regional Environment Protection Agency (ARPA) of Puglia for providing PM10 mass concentrations, NASA Data Distribution and Archive Center for Processing and Providing MODIS AOD, NOAA Air Resource Laboratory for providing data from the HYSPLIT (HYbrid Single-Particle Lagrangian Integrated Trajectory) model, and the Team of the Meteorological Station of Universita' del Salento for the provision of ground wind speeds.

\section{References and Notes}

1. Gupta, P.; Christopher, S.A. Seven year particulate matter air quality assessment from surface and satellite measurements. Atmos. Chem. Phys. 2008, 8, 3311-3324.

2. Schaap, M.; Apituley, A.; Timmermans, R.M.A.; Koelemeijer, R.B.A.; De Leeuw, G. Exploring the relation between aerosol optical depth and PM2.5 at Cabauw, the Netherlands. Atmos. Chem. Phys. 2009, 9, 909-925.

3. Tsai, T.C.; Jeng, Y.-J.; Chu, D.A.; Chen, J.-P.; Chang, S.-C. Analysis of the relationship between MODIS aerosol optical depth and particulate matter from 2006 to 2008. Atmos. Environ. 2009, doi:10.1016/j.atmosenv.

4. Koelemeijer, R.B.A.; Homan, C.D.; Matthijsen, J. Comparison of spatial and temporal variations of aerosol optical thickness and particulate matter in Europe. Atmos. Environ. 2006, 40, 5304-5315.

5. Gupta, P.; Christopher, S.A.; Wang, J.; Gehrig, R.; Lee, Y.C.; Kumar, N. Satellite remote sensing of particulate matter and air quality over global cities. Atmos. Environ. 2006, 40, 5880-5892.

6. Schaap, M.; Timmermans, R.M.A.; Koelemeijer, R.B.A.; De Leeuw, G.; Builtjes, P.J.H. Evaluation of MODIS aerosol optical thickness over Europe using sun photometer observations. Atmos. Environ. 2008, 42, 2187-2197. 
7. Lelieveld, J.; Berresheim, H.; Borrmann, S.; Crutzen, P.J.; Dentener, F.J.; Fischer, H.; Feichter, J.; Flatau, P.J.; Heland, J.; Holzinger, R.; Korrmann, R.; Lawrence, M.G.; Levin, Z.; Markowicz, K.M.; Mihalopoulos, N.; Minikin, A.; Ramanathan, V.; Reus, M.D.; Roelofs, G.J.; Scheeren, H.A.; Sciare, J.; Schlager, H.; Schultz, M.; Siegmund, P.; Steil, B.; Stephanou, E.G.; Stier, P.; Traub, M.; Warneke, C.; Williams, J.; Ziereis, H. Global air pollution crossroads over the Mediterranean. Science 2002, 298, 794-799.

8. Santese, M.; De Tomasi, F.; Perrone, M.R. Advection patterns and aerosol optical and microphysical properties by AERONET over south-east Italy in the central Mediterranean. Atm. Chem. Phys. 2008, 8, 1881-1886.

9. Bergamo, A.; Tafuro, M.; Kinne, S.; De Tomasi, F.; Perrone, M.R. Monthly averaged anthropogenic aeorosol direct radiative forcing over the Mediterranean based on AERONET aerosol properties. Atmos. Chem. Phys. 2008, 8, 6995-7014.

10. Holben, B.N.; Eck, T.F.; Slutsker, I.; Tanré, D.; Buis, J.P.; Setzer, A.; Vermote, E.; Reagan, J.; Kaufman, Y.; Nakajima, T.; Lavenu, F.; Jankowiak, I.; Smirnov, A. AERONET: A federated instrument network and data archive for aerosol characterization. Rem. Sens. Environ. 1998, 66, 116.

11. Perrone, M.R.; Carofalo, I.; Dinoi, A.; Buccolieri, A.; Buccolieri, G. Ionic and elemental composition of TSP, PM10 and PM2.5 samples collected over South-East Italy. Nuovo Cimento 2009, DOI 10.1393/nbc/i2009-10770-2.

12. Perrone, M.R.; Bergamo, A.; Bellantone, V. Aerosol direct radiative forcing during Sahara dust intrusions in the central Mediterranean. Atmos. Chem. Phys. 2009, doi:10.5194/acpd-9-22539-2009.

13. De Tomasi, F.; Perrone, M.R. PBL and dust layer seasonal evolution by lidar and radiosounding measurements over a peninsular site. Atoms. Res. 2006, 80, 86-103.

14. De Tomasi, F.; Perrone, M.R. Lidar measurements of tropospheric water vapor and aerosol profiles over southeastern Italy. J. Geophys. Res. 2003, 108, 4286-4297.

15. Giugliano, M.; Lonati, G.; Budelli, P.; Romele, L.; Tardivo, R.; Grosso, M. Fine particulate (PM2.5-PM1) at urban sites with different traffic exposure. Atoms. Environ. 2005, 39, 2421-2431.

16. Remer, L.A.; Kaufman, Y.J.; Tanre, D.; Mattoo, S.; Chu, D.A.; Martins, J.V.; Li, R.R.; Ichoku, C.; Levy, R.C.; Kleidman, R.G.; Eck, T.F.; Vermote, E.; Holben, B.N. The MODIS Aerosol Algorithm, Products and Validation. J. Atmos. Sci. 2005, 62, 947-973.

17. Levy, R.C.; Remer, L.A.; Mattoo, S.; Vermote, E.F.; Kaufman, Y.J. Second-generation operational algorithm: Retrieval of aerosol properties over land from inversion of Moderate Resolution Imaging Spectroradiometer spectral reflectance. J. Geophys. Res. 2007, 112, D13211.

18. Levy, R.C.; Remer, L.A.; Dubovik, O. Global aerosol optical properties and application to Moderate Resolution Imaging Spectroradiometer aerosol retrieval over land. J. Geophys. Res. 2007, 112, D13210.

19. Remer, L.A.; Tanré, D.; Kaufman, Y.J.; Levy, R.; Mattoo, S. Algorithm for remote sensing of troposphere aerosol from MODIS: Collection 005. Available online: http://modisatmos.gsfc.nasa.gov/_docs/MOD04:MYD04 (accessed on 12 May 2010). 
20. Kaufman, Y.J.; Tanré, D.; Remer, L.A.; Vermote, E.F.; Chu, A.; Holben, B.N. Operational remote sensing of tropospheric aerosol over the land from EOS-MODIS. J. Geophys. Res. 1997, 102, 17051-17068.

21. Tanré, D.; Kaufman, Y.J.; Herman, M.; Mattoo, S. Remote sensing of aerosol properties over oceans using the MODIS/EOS spectral radiances. J. Geophys. Res. 1997, 102, 16971-16988.

22. Santese, M.; De Tomasi, F.; Perrone, M.R. Moderate Resolution Imaging Spectroradiometer (MODIS) and Aerosol Robotic Network (AERONET) retrievals during dust outbreaks over the Mediterranean. J. Geophys. Res. 2007, 112, D18201.

23. Santese, M.; De Tomasi, F.; Perrone, M.R. AERONET versus MODIS aerosol parameters at different spatial resolutions over southeast Italy. J. Atmos. Sci. 2007, 112, D10214.

24. Perrone, M.R.; Santese, M.; Tafuro, A.M.; Holben, B.; Smirnov, A. Aerosol load characterization over South-East Italy for one year of AERONET sun-photometer measurements. Atoms. Res. 2005, 75, 111-133.

25. Engel-Cox, J.A.; Holloman, C.H.; Coutant, B.W.; Hoff, R.M. Qualitative and quantitative evaluation of MODIS satellite sensor data for regional and urban scale air quality. Atmos. Environ. 2004, 38, 2495-2509.

26. Martins, J.V.; Tanre, D.; Remer, L.A.; Kaufman, Y.J.; Mattoo, S.; Levy, R. MODIS Cloud screening for remote sensing of aerosols over oceans using spatial variability. Geophys. Res. Lett. 2002, 29, 10.1029/2001GL013252.

27. Ackerman, S.A.; Strabala, K.I.; Menzel, W.P.; Frey, R.A.; Moeller, C.C.; Gumley, L.E. Discriminating clear sky from clouds with MODIS. J. Geophys. Res. 1998, 103, 32139-32140.

28. Gao, B.C.; Yang, P.; Han, W.; Li, R.R.; Wiscombe, W.J. An algorithm using visible and $1.38 \mathrm{~mm}$ channels to retrieve cirrus reflectances from aircraft and satellite data. IEEE Trans. Geosci. Remote Sens. 2002, 40, 1659-1668.

29. Kaufman, Y.J.; Koren, I.; Remer, L.A.; Tanré, D.; Ginoux, P.; Fan, S. Dust transport and deposition observed from the Terra-Moderate Resolution Imaging Spectroradiometer (MODIS) spacecraft over the Atlantic Ocean. J. Geophys. Res. 2005, 110, D10S12.

30. Wen, G.; Cahalan, R.F.; Tsay, S.; Oreopoulos, L. Impact of cumulus cloud spacing on Landsat atmospheric correction and aerosol retrieval. J. Geophys. Res. 2001, 106, 12129-12138.

31. Holben, B.N.; Tanré, D.; Smirnov, A. An emerging ground-based aerosol climatology: Aerosol optical depth from AERONET. J. Geophys. Res. 2001, 106, 9807-9826.

32. Smirnov, A.; Holben, B.N.; Dubovik, T.F.; Slutsker, O. Cloud-screening and quality control algorithms for the AERONET database. Remote Sens. Environ. 2000, 73, 337-349.

33. Gai, C.S.; Li, X.Q.; Zhao, F.S. Mineral aerosol properties observed in the northwest region of China. Glob. Planet. Changes 2006, 52, 173-181.

34. Chu, D.A.; Kaufman, Y.J.; Zibordi, G.; Chern, J.D.; Mao, J.; Li, C.; Holben, B.N. Global monitoring of air pollution over land from the Earth observing System-Terra Moderate Resolution Imaging Spectroradiometer (MODIS). J. Geophys. Res. 2003, 108, D21.

35. Hybrid Single Particle Lagrangian Integrated Trajectory Model. Available online: http://www.arl.nooa.gov/ready/hysplit4.html (accessed on 10 May 2010). 
36. NOAA/ ESRL Radiosonde Database. Available online: http:// raob.fsl.noaa.gov/ (accessed on 10 May 2010).

37. Sicard, M.; Pérez, C.; Rocadenbosch, F.; Baldasano, J.M.; García-Vizcaino, D. Mixed-layer depth determination in the Barcelona Coastal Area from regular LiDAR measurements: Methods, results and limitations. Bound.-Layer Meteor. 2006, 119, 135-157.

38. Holzworth, G.C. Mixing Heights, Wind Speeds, and Potential for Urban Air Pollution throughout the Contiguous United States; Pub. No. AP-101, Office of Air Programs, U.S. Environmental Protection Agency: Washington, DC, USA, 1972; pp. 3-34.

39. Analytical Back Trajectories. Available online: http://croc.gsfc.nasa.gov/aeronet/IMAGES//Y06/ M09/ktraj_tlk_7bck06091112.ps147001.gif (accessed on 10 May 2010).

40. MODIS true colour images. Available online: http://rapidfire.sci.gsfc.nasa.gov/ realtime/single.php?T062541000 (accessed on 10 May 2010).

41 Kaiser, J.W.; Suttie, M.; Flemming, J.; Morcrette, J.-J.; Boucher, O.; Schultz, M.G. Smoke in the air. ECMWF Newslett. 2009, 119, 9-15.

( 2010 by the authors; licensee MDPI, Basel, Switzerland. This article is an Open Access article distributed under the terms and conditions of the Creative Commons Attribution license (http://creativecommons.org/licenses/by/3.0/). 